\title{
Advanced Fuel Cycle Economic Sensitivity Analysis
}

David Shropshire Kent Williams

J.D. Smith

Brent Boore

December 2006

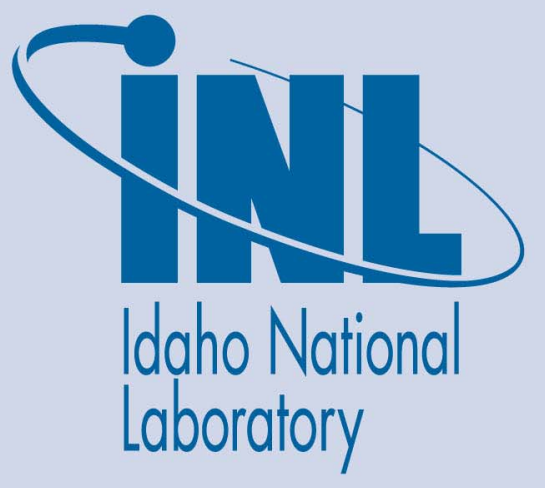

The INL is a U.S. Department of Energy National Laboratory operated by Battelle Energy Alliance 
INL/EXT-06-11947

\title{
Advanced Fuel Cycle Economic Sensitivity Analysis
}

\author{
David Shropshire ${ }^{1}$ \\ Kent Williams ${ }^{2}$ \\ J.D. Smith ${ }^{3}$ \\ Brent Boore ${ }^{4}$
}

${ }^{1}$ Idaho National Laboratory

${ }^{2}$ Oak Ridge National Laboratory

${ }^{3}$ Sandia National Laboratory

${ }^{4}$ Washington Savannah River Company

December 2006

\section{Idaho National Laboratory \\ Idaho Falls, Idaho 83415}

Prepared for the

U.S. Department of Energy

Office of Nuclear Energy

Under DOE Idaho Operations Office

Contract DE-AC07-05ID14517 
INTENTIONALLY BLANK 


\section{EXECUTIVE SUMMARY}

An economic analysis was performed on four fuel cycles to produce an initial baseline for fuel cycle cost analysis. The analysis was prepared by using the Generation IV Economic Modeling Working Group G4-ECONS spreadsheet model and Decision Programming Language software. Reference costs were obtained through Advanced Fuel Cycle Initiative studies, industry cost data, international papers, and university papers. The analysis produced comparative unit fuel cycle cost distributions for a range of fuel cycles including: once-through, sustained thermal with fast recycle, sustained fast recycle, and thermal recycle. The fuel cycle costs evaluated in this study typically represent 15 to $25 \%$ of the total cost of electricity. The remaining components of the overall nuclear unit electricity cost (not included in this study) consist of the reactor-related costs (capital, operating, and decommissioning) and are highly dependent on the type and size of the reactor, deployment assumptions (including financing), and maturity of the technology. Cost parity may not exist between fast and thermal reactors. Future analysis will combine the fuel cycle costs with the reactor-related costs (with associated uncertainties) to produce a total levelized unit electricity cost for nuclear power.

The economic analysis showed large cost uncertainties with all the fuel cycle strategies, with levelized equilibrium fuel cycle costs ranging from approximately 5 to $21 \mathrm{mills} / \mathrm{kW} \mathrm{h}$. The study concludes that additional U.S. based design studies are needed to reduce the cost uncertainties with respect to the total fuel cycle and reactor costs. The main cost discriminator on the once-through cycle is uranium mining and milling, varying \pm 1 mills $/ \mathrm{kW} \mathrm{h}$. The main cost discriminator for the closed fuel cycles is recycled fuel fabrication, varying from \pm 3 mills $/ \mathrm{kW} \mathrm{h}$. The impact from separations costs are on par with the costs of process waste conditioning and disposition at $\pm 0.5 \mathrm{mills} / \mathrm{kW}$ h. There are unknown cost risks due to limited technical process maturity and operational experience with pyrochemical separation and fabrication, and to a lesser degree-aqueous separation.

Starting with this initial cost baseline, future what-if analysis can be performed and compared to the assumptions and costs shown in this report. Additional studies will also consider reactor costs with uncertainties, additional fuel cycle options (e.g., 2-tier thermal recycle with fast recycle), system uncertainties that influence costs, economic trade-offs and sensitivities, using dynamic models to evaluate non-equilibrium conditions, and comparing nuclear energy costs to those projected for other future base-load electrical energy systems (e.g., clean coal). 


\section{CONTENTS}

EXECUTIVE SUMMARY iv

ACRONYMS viii

1. INTRODUCTION 1

1.1 Computational Approach and Prior Studies ................................................................. 2

1.2 Advanced Fuel Cycle Initiative Estimation Approach .................................................. 2

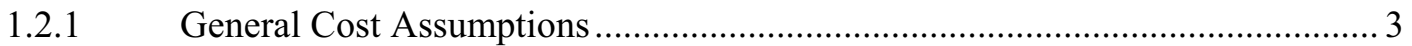

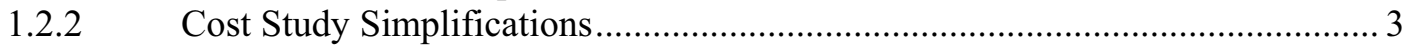

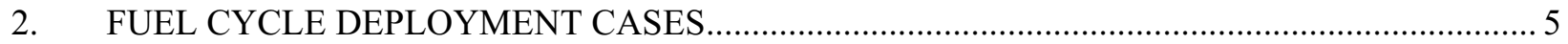

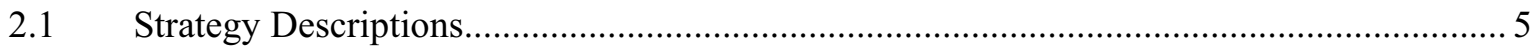

2.1.1 Case 1: Generation III+ LWR Operating on an Open Fuel Cycle ...................... 5

2.1.2 Case 2: Reprocessed Fuel from Multiple Number of Generation III+ LWRs Providing Make-up Fuel for a 1,000 MWe Fast Burner Reactor; A Hybrid Fuel Cycle 5

2.1.3 Case 3: A Generation IV Sodium-cooled Fast Reactor Operating on a Closed Pyrochemical Fuel Cycle ....................................................................... 6

2.1.4 Case 4: Thermal Recycle of DU,Pu,Np MOX drivers and EU,Am,Cm MOX targets in a Generation III+ LWR . .6

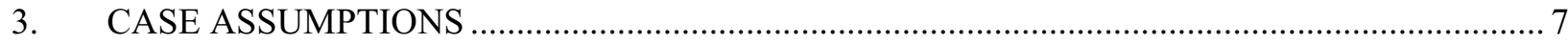

3.1 Case 1: Generation III+ LWR Operating on an Open Fuel Cycle ...................................... 7

3.1.1 Case 1: Front-end Fuel Cycle Requirements................................................... 10

3.1.2 Case 1: Back-End Fuel Cycle Requirements .................................................. 11

3.2 Case 2: Reprocessed Fuel from Multiple Number of Generation III+ LWRs Providing Make-up Fuel for a 1,000 MWe Fast Burner Reactor: A Hybrid Fuel Cycle........... 12

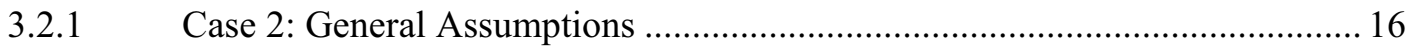

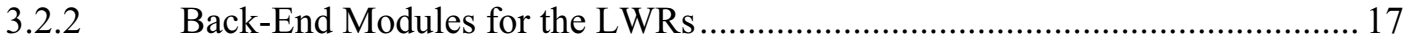

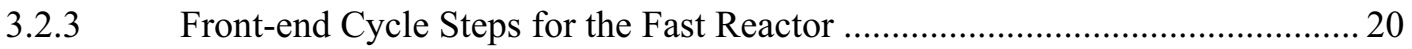

3.2.4 Back-End Modules for the Converter Fast Reactor (CFR) .............................. 21

3.3 Case 3: A Generation IV Sodium-cooled Fast Reactor Operating on a Closed

Pyrochemical Fuel Cycle ....................................................................................... 23

3.3.1 Case 3: Module D2 (Metal Fuel Fabrication) Assumptions...............................2 26

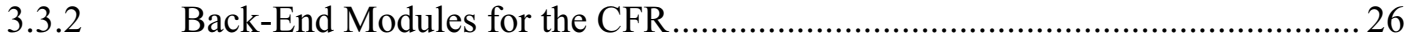


3.4 Case 4: Thermal Recycle of DU, Pu, Np MOX drivers and EU, Am, Cm MOX targets in a Generation III+ LWR

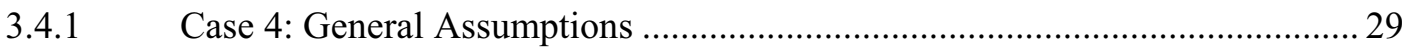

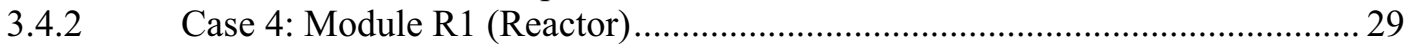

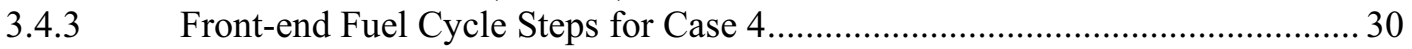

3.4.4 Back-end Fuel Cycle Steps for Case 4 ........................................................... 30

4. FUEL CYCLE COST BASIS AND DATA UNCERTAINTY RANGES ................................... 33

4.1 Cost Assumptions on Fuel Cycle Front-End ............................................................ 34

4.2 Cost Assumptions Regarding Separations and Refabrication of Fuels ............................. 34

4.3 Cost Assumptions on Fuel Cycle Back-End.................................................................. 35

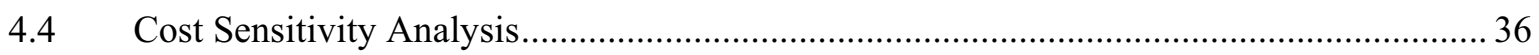

5. THE UNIT FUEL CYCLE COST IN PERSPECTIVE TO THE OVERALL BUSBAR COST OF NUCLEAR ELECTRIC POWER AND POSSIBLE WASTE RADIOISOTOPE TRANSMUTATION MISSIONS

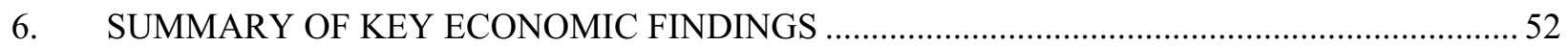

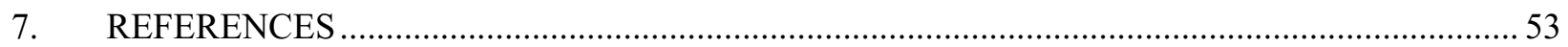

Appendix A-Fuel Cycle Cost Comprehensive Spreadsheet ............................................................... 54

\section{FIGURES}

Figure 1. Case 1: Generation III+ LWR operating on an open fuel cycle. …........................................... 8

Figure 2-1. Case 2: Reprocessed fuel from multiple number of generation III+ LWRs providing make-up fuel for a 1,000 MWe fast burner Reactor: A hybrid fuel cycle.

Figure 2-2. Case 2: Reprocessed fuel from multiple number of generation III+ LWRs providing make-up fuel for a 1,000 MWe fast burner reactor: A hybrid fuel cycle.

Figure 2-3. Case 2: Reprocessed fuel from multiple number of generation III+ LWRs providing make-up fuel for a 1,000 MWe fast burner reactor: A hybrid fuel cycle.

Figure 3. Case 3: A generation IV sodium-cooled fast reactor operating on a closed pyrochemical fuel cycle.

Figure 4. Case 4: Thermal recycle of DU, Pu, Np MOX drivers and EU, Am, Cm MOX targets in a generation III+ LWR.

Figure 5. Cumulative risk profile using 3 point data and normal distribution. .37 
Figure 6. Frequency risk profile using Monte Carlo Analysis at $\pm 50 \%$ nominal data. 38

Figure 7. Frequency risk profile using Monte Carlo triangular distribution. 39

Figure 8. Value tornado diagram-Case 1 perspective. 42

Figure 9. Value tornado diagram-Case 1 and 2 comparison. 43

Figure 10. Value tornado diagram-Case 1 and 3 comparison. 44

Figure 11. Value tornado diagram-Case 1 and 4 comparison. 45

Figure 12. Value tornado diagram-Case 2 and 3 comparison. .46

Figure 13. Value tornado diagram-Case 2 and 4 comparison. .47

Figure 14. Value tornado diagram-Case 3 and 4 comparison. 48

\section{TABLES}

Table 1. 2006 AFC comparison report comparison of fuel cycle cost ranges across strategies. 2

Table 2. Mass fraction percentiles from burning UOX fuel. 18

Table 3. Mass fraction percentiles from burning converter fast reactor fuel. 21

Table 4. Mass fraction percentiles from burning fast reactor fuel. 27

Table 5. Mass fraction percentiles from burned UOX and MOX used fuel. 31

Table 6. Fuel cycle module cost uncertainty. 33

Table 7. Statistical data for the Monte Carlo Analysis using $\pm 50 \%$ nominal data. 40

Table 8. Statistical data for analysis using low, nominal, high data in normal distribution. 40

Table 9. Comparison of fuel cycle cost ranges from the Comparison Report to the current study. 41

Table 10. G4-ECONS breakdown of the LUEC for a generation III+ PWR operating on an open cycle under de-regulated higher-risk conditions ( $10 \%$ real discount rate).

Table 11. G4-ECONS breakdown of the LUEC for a generation III+ PWR operating on an open cycle under regulated utility, lower-risk conditions ( $5 \%$ real discount rate). 50 


\section{ACRONYMS}

ABB-CE Asea Brown Boveri-Combustion Engineering, Inc.

AFC Advanced Fuel Cycle

AFCI Advanced Fuel Cycle Initiative

ALWR Advanced Light-Water Reactor

ANL Argonne National Laboratory

CFR converter fast reactor

CE central valve

COE cost of electricity

CR conversion ratio

CY calendar year

D\&D decommissioning and decontamination

DPL Decision Programming Language

DU depleted uranium

ECONS Excel-based Calculation of Nuclear Systems

EMWG Gen IV Economic Modeling Working Group

EPRI Electric Power Research Institute

EU enriched uranium

EV expected value

FP fission product

FR fast reactor

FY fiscal year

GNEP Global Nuclear Energy Partnership

GTCC Greater-than Class C (low level waste)

HA higher actinides

HM heavy metal 


\begin{tabular}{|c|c|}
\hline HLW & high-level waste \\
\hline INL & Idaho National Laboratory \\
\hline JSFR & Japanese Sodium-cooled Fast Reactor \\
\hline LLW & low-level waste \\
\hline LUEC & Levelized Unit Electricity Cost \\
\hline LWR & light water reactor \\
\hline MOX & mixed oxide \\
\hline МТНМ & metric tons of heavy metal \\
\hline NPP & nuclear power plant \\
\hline NTS & Nevada Test Site \\
\hline NWPA & Nuclear Waste Policy Act of 1982 \\
\hline O\&M & operating and maintenance \\
\hline OECD & Organization for Economic Cooperation and Development \\
\hline ORNL & Oak Ridge National Laboratory \\
\hline PWR & pressurized water reactor \\
\hline RCRA & Resource Conservation and Recovery Act \\
\hline REPU & reprocessed uranium \\
\hline SNF & spent nuclear fuel \\
\hline SS & stainless steel \\
\hline SWU & separative work unit \\
\hline TRU & transuranic waste \\
\hline UOX & uranium oxide (type of fuel) \\
\hline UREX+ & uranium extraction plus (separation process) \\
\hline VHTR & Very High Temperature Reactors \\
\hline
\end{tabular}




\section{FUEL CYCLE ECONOMIC SENSITIVITY ANALYSIS}

\section{INTRODUCTION}

This fuel cycle economic analysis was performed on four fuel cycles to provide a baseline for initial cost comparison for the Advanced Fuel Cycle Initiative (AFCI) program. The fuel cycles represented specific applications of the once-through fuel cycle, thermal/fast recycling, fast reactor (FR) recycling, and recycling in thermal reactors. From the data compiled for this report, further analysis may be performed to investigate variations on these fuel cycle schemes and to test new assumptions on the cost, performance, or operating parameters used in this study.

This report developed and compared only the fuel cycle cost component of the total busbar cost of electricity (COE) from the reactor. The computation was based on an equilibrium steady-state analysis which accounts for reactor performance in kilowatt-hours of electricity production, but does not explicitly address reactor costs. As a general rule of thumb, nuclear fuel cycle costs run about $20 \%$ of the total COE. Assumptions were made on the type of reactor and the associated performance in terms of impacts to front-end fuel demands and back-end processing requirements. A process flow diagram was developed to define the process steps or unit cost modules, annual mass flow rates, and required facility capacities. The Generation IV Economic Modeling Working Group (EMWG) G4 Excel-based Calculation of Nuclear Systems (ECONS) calculation of nuclear systems spreadsheet was adapted to estimate the fuel cycle costs (Miller and Williams 2006). A "deterministic" or "single-point" base case fuel cycle cost spreadsheet was prepared for each of the four fuel cycle schemes.

A cost sensitivity analysis was performed using the Decision Programming Language (DPL) uncertainty software. A range of unit costs, spanning from the lowest to the highest expected value, was developed for each cost module to create a probabilistic cost distribution. The cost range was developed to cover a range of uncertainties resulting from front-end fuel cycle market fluctuations, reactor performance such as energy output, actinide separation, recycled fuel fabrication technology performance, and waste disposition uncertainties. The cost data was selected by cost analysts based on the data compiled form industry cost data, international papers, and nuclear power-related cost studies from the Massachusetts Institute of Technology (MIT), Harvard, and the University of Chicago. Understanding the risks due to the potential cost uncertainty of the open and closed fuel cycle processes in the uncertainty analysis increased the value of the analyses for the cost data.

The analysis resulted in broad cost distributions for the four fuel cycle cases. There is significant overlap between the cost distributions of the cases. The major fuel cycle cost discriminators are uranium mining and milling costs, and recycled fuel fabrication. Additional variables which have a large potential impact include the high level waste/spent nuclear fuel (HLW/SNF) repository, and reprocessing and waste conditioning. Separations costs, in spite of the high cost uncertainty, are not decision drivers in these cases. The impacts of separations are on par with the costs due to process waste conditioning and disposition. For thermal/fast recycling, the combined cost impact from high-end costs for aqueous and pyrochemical separations would only total about $1 \mathrm{mill} / \mathrm{kW} \mathrm{h}$. However, there are unknown cost risks due to less technical process maturity and operational experience associated with pyrochemical separations than aqueous processing. 
The insight from this analysis is that the costs for the open fuel cycle are driven by uncertainties in open-market pricing for uranium and front-end fuel services, and the policies defining the costs for used nuclear fuel disposition. Alternatively, closed fuel cycle costs are driven by technology uncertainties for "hot" (remote handling) fuel fabrication, actinide separation, and process waste disposition. In the closed fuel cycle case, the resources needed to produce reactor fuels will be less sensitive to market dynamics and will produce less waste subject to disposal in geological repositories.

\subsection{Computational Approach and Prior Studies}

This study is based on the AFCI cost collection and economic studies prepared for the 2006 Advanced Fuel Cycle (AFC) Cost Basis report (Shropshire 2006). A preliminary study of fuel cycle strategies was prepared for the 2006 update of the AFCI Comparison Report (DOE 2006). The results from Table 1 of the report are presented below in Table 1 of this document. These costs were subsequently updated in this AFC Economic Sensitivity Analysis.

Table 1.2006 AFC comparison report comparison of fuel cycle cost ranges across strategies.

\begin{tabular}{|c|c|c|c|c|}
\hline Strategies & $\begin{array}{l}\text { Complete } \\
\text { once-through } \\
\text { fuel cycle }\end{array}$ & $\begin{array}{l}\text { Sustained } \\
\text { thermal/fast } \\
\text { recycling }\end{array}$ & $\begin{array}{l}\text { Sustained fast } \\
\text { reactor recycling }\end{array}$ & $\begin{array}{l}\text { Recycling in } \\
\text { thermal reactors }\end{array}$ \\
\hline \multicolumn{5}{|c|}{ Illustrative technology options that could implement strategy } \\
\hline \multicolumn{5}{|c|}{$\begin{array}{l}\text { Objective } 4 \text {. Improve fuel cycle management, while continuing competitive fuel cycle economics and excellent } \\
\text { safety performance of the entire nuclear fuel cycle system. }\end{array}$} \\
\hline $\begin{array}{l}\text { Fuel cycle cost ranges* } \\
\text { (within } 95 \% \text { cost } \\
\text { uncertainty bounds) }\end{array}$ & $\begin{array}{l}4.3 \text { to } 6.2 \\
\text { mills } / \mathrm{kW} \mathrm{h}\end{array}$ & $\begin{array}{l}4.4 \text { to } 6.5 \\
\text { mills } / \mathrm{kW} \mathrm{h}\end{array}$ & $\begin{array}{l}4.9 \text { to } 7.7 \\
\text { mills } / \mathrm{kW} \mathrm{h}\end{array}$ & $\begin{array}{l}6.7 \text { to } 10.8 \\
\text { mills } / \mathrm{kW} \mathrm{h}\end{array}$ \\
\hline
\end{tabular}

* Does not include the reactor cost portion of the Cost of Electricity

The cost ranges reflect uncertainty in key input parameters for a specific case; cost ranges do not reflect uncertainty in reactor capital cost or reactor non-fuel operations and maintenance (O\&M) costs nor different ways to implement each strategy. For the thermal recycle, mixed oxide fuels (MOX) are used to recycle transuranic elements. For thermal/fast recycling and fast recycling, metal alloy fuel in fast reactors recycles the transuranic elements.

\subsection{Advanced Fuel Cycle Initiative Estimation Approach}

This initial assessment provides a baseline for discussion and subsequent fine tuning of the assumptions driving the comparison of costs of fuel cycle strategies for cost, performance, and operating parameters.

The AFCI estimating approach is based on an equilibrium fuel cycle condition which provides an initial tool for comparison of open and closed fuel cycles. The analysis does not include dynamic conditions such as start-up, ramp-down, end-of-life conditions, intermittent or long-term storage strategies, transportation, or the reactor costs. Fuel cycle mass flows and costs were calculated using the fuel cycle analysis methodology in the G4-ECONS spreadsheet model developed by the Gen IV EMWG. The model uses the estimating approach that was developed by the EMWG and was reported in the Cost Estimating Guideline for Generation IV Nuclear Energy Systems (Miller and Williams 2006). Fuel cycle cost uncertainties were evaluated using DPL. The spreadsheet analysis was performed on four fuel cycles 
to provide modeling insights to overall facility capacity requirements and flow rates. This analysis provides a baseline for comparison of the broad options, which can be used for subsequent analysis.

\subsubsection{General Cost Assumptions}

- A general conservative approach using existing-conventional practices was taken to define the assumptions used in this analysis. For example, the assumptions include waste form and operational efficiencies, based on today's understanding of process technologies. In actual practice, improved and streamlined processes and technologies would be deployed to increase efficiencies and minimize costs.

- $\quad$ The analysis was based on equilibrium fuel cycles with yearly material flows. Even if times between reactor refuelings were greater than one year, the flow data was annualized to expedite the economic analysis.

- $\quad$ Large centralized aqueous separations plants (3,000 MT/yr), rather than multiple regional plants, would be deployed to realize gains from economy of scale (for aqueous reprocessing of light water reactor [LWR] used fuel).

- $\quad$ Pyrochemical separation/refabrication plants would be sized and sited coincident to one or more fast reactor facilities.

- The cost distributions used in this study are a projection of constant dollar nuclear fuel cycle costs $15+$ yrs into the future, and are presented in current year dollars for cycle year 2006 (CY-2006). A summary of the fuel cycle costs used in this analysis is provided in Appendix A.

- $\quad$ Nuclear power will grow in the United States and internationally at a pace to maintain or exceed the current electricity share. Advanced light water reactors (ALWRs), and Gen IV thermal and fast reactors will be developed to support commercial deployment. This growth is predicated on resolution of used fuel management and risk assumptions, and that incentives (e.g., loan guarantees) are provided to industry to build the first plants. Significant growth of nuclear power could result from lower overnight capital costs and the introduction of a carbon tax.

- $\quad$ Both open and closed fuel cycles are likely to be deployed in the United States.

\subsubsection{Cost Study Simplifications}

- Transportation costs and logistics were not specifically evaluated in this study. The front-end transportation costs are included in each front-end fuel cycle unit cost, and on the back-end fuel cycle costs. The cost of shipment of used fuel to the HLW repository is included in the waste disposal cost. Transportation costs are not expected to be cost discriminators between the cases; however, transportation costs may be a significant risk contributor in health-effects and safety analysis.

- The costs for expansion of the first HLW geologic repository beyond 70,000 metric tons of heavy metal (MTHM) or costs for subsequent repositories were not evaluated. Also, possible changes to the Nuclear Waste Policy Act of 1982 (NWPA) (42 U.S.C. 10101) were not evaluated for this study.

- As mentioned previously, the costs of the reactor were not included in this study. A discussion of the impact of the fuel cycle cost to the total cost of energy is included in Section 5, "The Unit Fuel 
Cycle Cost in Perspective to the Overall Busbar Cost of Nuclear Electric Power and Possible Waste Radioisotope Transmutation Missions.” 


\section{FUEL CYCLE DEPLOYMENT CASES}

The fuel cycle cases in this study were chosen to represent one option for implementing each of the four possible generic AFCI strategies. A strategy is a general approach to fuel management that encompasses a range of options with similar basic characteristics. The strategy identifies which materials are recycled (if any), the type of nuclear power plant utilizing the fuel, the type of used fuel processing technology, and which materials, used fuel or separated products, go to geologic disposal.

For each of the fuel cycle cases, the cost ranges correspond to a particular case within each strategy, but the cost ranges do not correspond to the wide range of ways to implement each strategy. For example, Very High-Temperature Reactors (VHTRs) can be used in some of the strategies, but influence on cost is not addressed. Subsequent to this analysis, other strategies can be developed using different reactor and performance assumptions, optimized mass flows, and facility operational characteristics that have the potential to reduce the uncertainties of the fuel cycle cost and the total cost of energy. This analysis can be expanded with reactor cost data to provide a total unit cost of electricity for these cases and additional strategies that may be considered. The analysis will become more conclusive when the total costs of energy are considered.

\subsection{Strategy Descriptions}

\subsubsection{Case 1: Generation III+ LWR Operating on an Open Fuel Cycle}

This is the current U.S. strategy of once-through UO2 fuel use. All the components of used fuel are kept together and are ultimately sent to a geologic repository.

\subsubsection{Case 2: Reprocessed Fuel from Multiple Number of Generation III+ LWRs Providing Make-up Fuel for a 1,000 MWe Fast Burner Reactor; A Hybrid Fuel Cycle}

This strategy is referred to as "sustained thermal/fast recycle" with a symbiotic mix of thermal and fast reactors which recycle transuranic elements from used fuel repeatedly until nearly all of the transuranic elements are destroyed. The introduction of fast reactors makes this strategy sustainable from the repository standpoint. The accumulation of transuranic elements during repeated recycle passes is controlled and limited by fast reactors serving as transuranic element burners.

Fission products and only transuranic waste (TRU) processing losses would go to geologic disposal, but transuranic elements would not. Reprocessed uranium from used fuel and most of the enrichment "tails" in depleted uranium (DU) would be disposed of as low-level waste (LLW). This strategy requires a certain fraction of the nuclear power plants in the overall nuclear power plant (NPP) fleet to be fast reactors. Because of the significance of this process, spent fuel reactor (SFR) type nuclear power plants are being researched extensively by the Generation IV Nuclear Energy Systems initiative. 


\subsubsection{Case 3: A Generation IV Sodium-cooled Fast Reactor Operating on a Closed Pyrochemical Fuel Cycle}

This strategy would use Generation IV fast reactors and is referred to as "sustained fast reactor recycling." The strategy recycles both uranium and transuranic elements repeatedly until nearly all available energy is extracted. Phasing out thermal reactors in favor of fast reactors means that even the non-fissile but fertile U-238 isotope of uranium will ultimately serve as fuel. Essentially no uranium or transuranic elements would be wasted, there would only be processing losses. As with other recycle strategies, long-lived fission products would tend to go to geologic disposal, and short-lived fission products would be stored and ultimately disposed of as LLW after sufficient decay. Therefore, this strategy is sustainable both in terms of repository constraints and uranium ore resources.

\subsubsection{Case 4: Thermal Recycle of DU,Pu,Np MOX drivers and EU,Am,Cm MOX targets in a Generation III+ LWR}

This strategy involves recycling in thermal reactors only. Reprocessed-uranium and fission products would be disposed of as LLW. Transuranic elements, such as plutonium, neptunium, americium, etc., would be recycled several times. The transuranic elements would eventually accumulate and require geologic disposal. Long-lived fission products would also go to geologic disposal, and short-lived fission products would be stored, and then ultimately disposed of as LLW.

This strategy uses existing types of nuclear power plants, which are all thermal reactors. Thermal recycle could involve the recycling of various elements including UOX (uranium oxide), Pu-Np-MOX and Am-Cm-MOX in LWRs. Case 4 involves the study of the most complex of these options including the Am-Cm-MOX recycle, which involves fabrication of these special "targets." Additional thermal

options could be studied, such as those for inert matrix fuels which have the potential to reduce costs, but insufficient data exists to make a comparison. 


\section{CASE ASSUMPTIONS}

The assumptions for each of the four cases are described in the remainder of this analysis. These assumptions are critical to defining the appropriate fuel cycle components, mass flows, and the application of the cost data. Along with the assumptions, a visual description of each of the cases is provided in Figures 1-4.

\subsection{Case 1: Generation III+ LWR Operating on an Open Fuel Cycle}

The process flow diagram shown in Figure 1 describes the linkage between fuel cycle modules, reactor capacity and energy output, recycling paths and operations, and primary mass flows. 


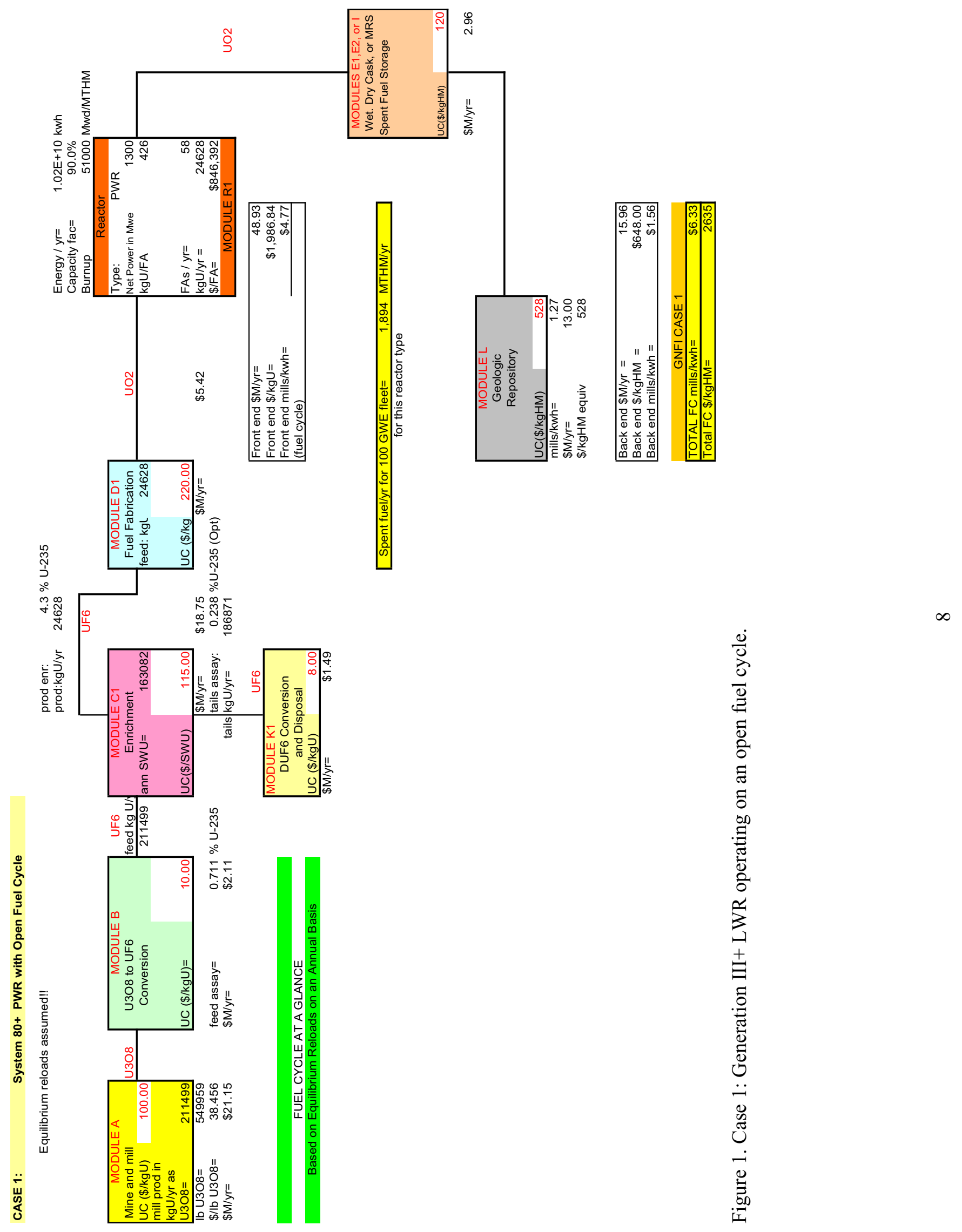


Fuel cycle material balance and cost data were available for the Generation III+ pressurized water reactor, Asea Brown Boveri-Combustion Engineering, Inc. (ABB-CE) System 80+ PWR (pressurized water reactor). This reactor was used as the starting point for calculating the throughput requirements for the other fuel cycle steps of ore mining and milling, yellowcake to UF6 conversion, uranium enrichment, fuel fabrication, and used fuel handling and disposal.

The following base attributes define the reactor and are achievable in current PWRs:

NOTE: All quantities are expressed on an annualized basis regardless of fuel cycle length.

- $\quad$ Power capacity of $1,300 \mathrm{MWe}$ (net).

- A capacity factor of $90 \%$.

- $\quad$ Annual electricity production of 10,200 million kilowatt-hours.

- $\quad$ An average fuel burnup of 51,000 MWd/MTHM.

- $\quad$ UO2 (UOX) zirc-clad pellet fuel with an average reload enrichment of 4.3\% U-235.

- A fuel cycle length time between refuelings of 1.77 years (fuel cycle material balance is annualized).

- A reactor operating life of 40 years.

- $\quad$ An average of 58 PWR assemblies/yr of $426 \mathrm{kgHM}$ each are replaced on an average annual basis for a total annual enriched uranium requirement of $24,628 \mathrm{~kg}$ uranium per year. This latter value is the basis for determining the annual throughput requirement for all other fuel cycle steps.

- The thermodynamic efficiency of the reactor is $34 \%$.

- $\quad$ All UOX fuel assemblies are assumed identical in enrichment and mass for purposes of model simplification.

- $\quad$ Reactor annual operations costs include LLW disposal of wastes such as paper, rags, resins, and contaminated equipment, but LLW disposal costs, such as contaminated resins, from reactor operations are not included in the fuel cycle cost. The reactor O\&M cost is as per usual industry practice.

- Excluding the following dynamic conditions:

- $\quad$ Start-up and initial core cost

- $\quad$ Ramp-down or end-of-life

- $\quad$ Intermittent or long term storage strategies

- Transportation

- $\quad$ Reactor-related costs such as capital cost and amortization, O\&M costs, and decommissioning and decontamination (D\&D) costs. 


\subsubsection{Case 1: Front-end Fuel Cycle Requirements}

The equilibrium throughput stated above is for enriched uranium charged annually to the reactor. Assuming no process losses, this throughput is also applicable to the fuel fabrication (Module D1-1) process. For purposes of model simplification, no (zero) process losses are assumed for all fuel cycle steps. In reality, very small losses are experienced because the value of the materials, environmental concerns, and losses are always minimized by the processor.

In order to calculate the amount of natural uranium needed from the mining/milling step in Module A and conversion plant in Module B, a material balance must be drawn around the enrichment plant in Module $\mathrm{C} 1$. This plant is fed with natural assay UF6 and produces a U-235 enriched product, UF6 stream $(24,628 \mathrm{kgU} / \mathrm{yr}$ at $4.3 \% \mathrm{U}-235)$, and a U-235 depleted or "tails" stream. To close the material balance, a "tails assay" or depleted stream, U-235 concentration must be defined. A value of $0.238 \%$ U-235 was selected by the G4-ECONS fuel cycle model since this value "optimizes" the enriched product unit cost of $\$ / \mathrm{kgU}$ of enriched uranium (EU) product for which natural uranium ore costs must be balanced against enrichment separative work unit (SWU) costs. The resulting natural U-235 content of $0.711 \% \mathrm{U}-235$ feed requirement to the conversion and enrichment plants is $216,363 \mathrm{kgU} / \mathrm{yr}$. and $\mathrm{C} 1$.

The following assumptions are made concerning the front-end fuel cycle facilities Modules A, B,

\subsubsection{Case 1: Module A (Mining and Milling). The unit cost of mining and milling is a} market-based value based on contract pricing, and is subject to the vagaries of supply and demand energy commodity pricing. In the U.S. the cost is expressed in terms of $\$ / 1 \mathrm{bU} 3 \mathrm{O} 8$. A factor of $\sim 2.6$ converts the English unit to the metric $\$ / \mathrm{kgU}$.

The cost includes mining, milling, transportation to the converter, Module B, and all environmental and waste handling costs associated with mine tailings, mill waste disposal, and radon suppression for mine safety. Environmental compliance costs are also assumed included for in-situ solution mining.

The product delivered to the converter is "yellowcake," which is impure U3O8.

3.1.1.2 Case 1: Module B (U308 to UF6 Conversion). The unit cost of conversion is a market-based value based on contract pricing, and tends to move with the price for uranium ore mining and milling.

The unit conversion cost includes UF6 cylinder acquisition, processing, transportation of converted product to the enrichment plant, and all environmental compliance costs which includes LLW disposal.

The product delivered to the enrichment plant is natural assay $(0.711 \%$ U-235) UF6 (NATUF6) of an impurity level that meets the enricher feed specifications.

3.1.1.3 Case 1: Module C1 (Enrichment). The unit cost for uranium enrichment is expressed in $\$$ per kilogram separative work unit (\$/SWU). The SWU is a thermodynamic entity which represents the amount of effort or work required to split a multi-isotopic feed stream into an enriched and depleted fraction. A "value function" is used with G4-ECONS to calculate SWUs and is dependent on the desired U-235 isotopic concentrations of the streams entering and leaving the plant.

For this assessment, which looks toward future nuclear growth, enrichment is assumed to be performed by the gas centrifuge enrichment process because it is less energy intensive than the older 
gaseous diffusion process. Making the assumption that all environmental costs, including LLW disposal but not tails conversion/disposal, are covered in the unit SWU cost.

The unit cost of enrichment includes transportation of the enriched UF6 product (EUF6) in 2.5 ton cylinders to the fuel fabricator Module D1-1 and temporary storage of the depleted UF6 (DUF6) "tails" in 14-ton cylinders at the enrichment plant site.

Uranium enrichment is a competitive, mature industry; hence SWU costs/prices are market driven. The unit SWU cost moves somewhat in the same direction as mining and milling costs.

3.1.1.4 Case 1: Module D1 (Fuel Fabrication). The unit cost for fuel fabrication is expressed in $\$ / \mathrm{kg}$ of heavy metal (HM) which, in this case, is uranium in the form of ceramic uranium oxide (UO2). The HM mass does not include the mass of the zirconium or zirc alloy cladding, spacers, grids, etc. that make up around one-third of the mass of a typical fuel assembly. The cost of these zirc components is included in the unit cost of fuel fabrication.

The fuel fabricator receives EUF6, defluorinates it, and produces an EUO2 powder meeting a "fuel specification" morphology requirement. The powder is pressed into ceramic pellets which are sintered, ground, inspected, and loaded into zirconium tubes to produce "fuel rods." The rods are inserted into square grids to form the complete LWR fuel assembly.

The unit cost includes all of the above steps plus transportation of the finished fuel assemblies to the reactor. Also included are LLW disposal, hydrogen fluoride disposition or sale, and other environmental compliance costs.

3.1.1.5 Case 1: Module K1 (DUF6 Conversion and Disposal). Regulators are unlikely to allow permanent storage of DUF6 at the enrichment plant site. The DUF6 is assumed to be shipped to a facility which can convert the material to a more stable chemical form, in this case DU3O8. The conversion facility defluorinates the DUF6, converts it to a crude U3O8 powder, and packages the powder in a container suitable for shallow burial disposal at an LLW facility.

The unit conversion/disposal cost is applied to the enrichment plant tails stream and is expressed in \$ per kg DU handled.

Transportation of 14-ton DUF6 cylinders from the enrichment plant site and transportation of DU3O8 containers to the burial site are included in the unit cost.

Disposition costs/benefits from hydrogen fluoride neutralization or resale resulting from the defluorination step are included in the unit cost.

\subsubsection{Case 1: Back-End Fuel Cycle Requirements}

Used fuel assemblies are placed in the used fuel pool after discharge to cool for a few years. An equivalent annual number of "cooled" assemblies are assumed to be withdrawn from the pool to begin the used fuel disposition process. Fuels were assumed to be moved offsite and not require additional storage (Module E).

3.1.2.1 Case 1: Module L1 (Geologic Repository). The used fuel would be removed from wet storage and placed in casks at the reactor site or in an offsite pool. These assemblies are then transported in a cask to a geologic repository where the assemblies can be repackaged, if necessary, and placed in the tunnels. 
Unit costs for this step can be represented by an energy charge of mills per $\mathrm{kW} h$ fee such as mandated in the U.S. by the Nuclear Waste Policy Act or by a cost per kgHM value. A $1 \mathrm{mill} / \mathrm{kW}$ h fee would be equivalent to approximately $\$ 381 / \mathrm{kgHM}$ for a burn-up of 50,000 MWd/MTHM. The MTHM based cost becomes less for higher burnups at a fixed energy or millage fee.

The disposal fee is assumed to include casks, transportation, repackaging, placement, and perpetual monitoring.

3.1.2.2 Case 1: Other considerations. All fuel cycle unit costs are assumed to include an imbedded component for D\&D of the fuel cycle facility at the end of its life. This is normally handled by an escrow fund maintained by the facility owner/operator.

\subsection{Case 2: Reprocessed Fuel from Multiple Number of Generation III+ LWRs Providing Make-up Fuel for a 1,000 MWe Fast Burner Reactor: A Hybrid Fuel Cycle}

The Case 2 process flow includes all the modules shown in Case 1 except used fuel disposition at the repository, and continues with the uranium extraction (UREX) + separations plant in Figure 2-2, and then Figure 2-3 shows the recycle of actinides in a fast reactor. 


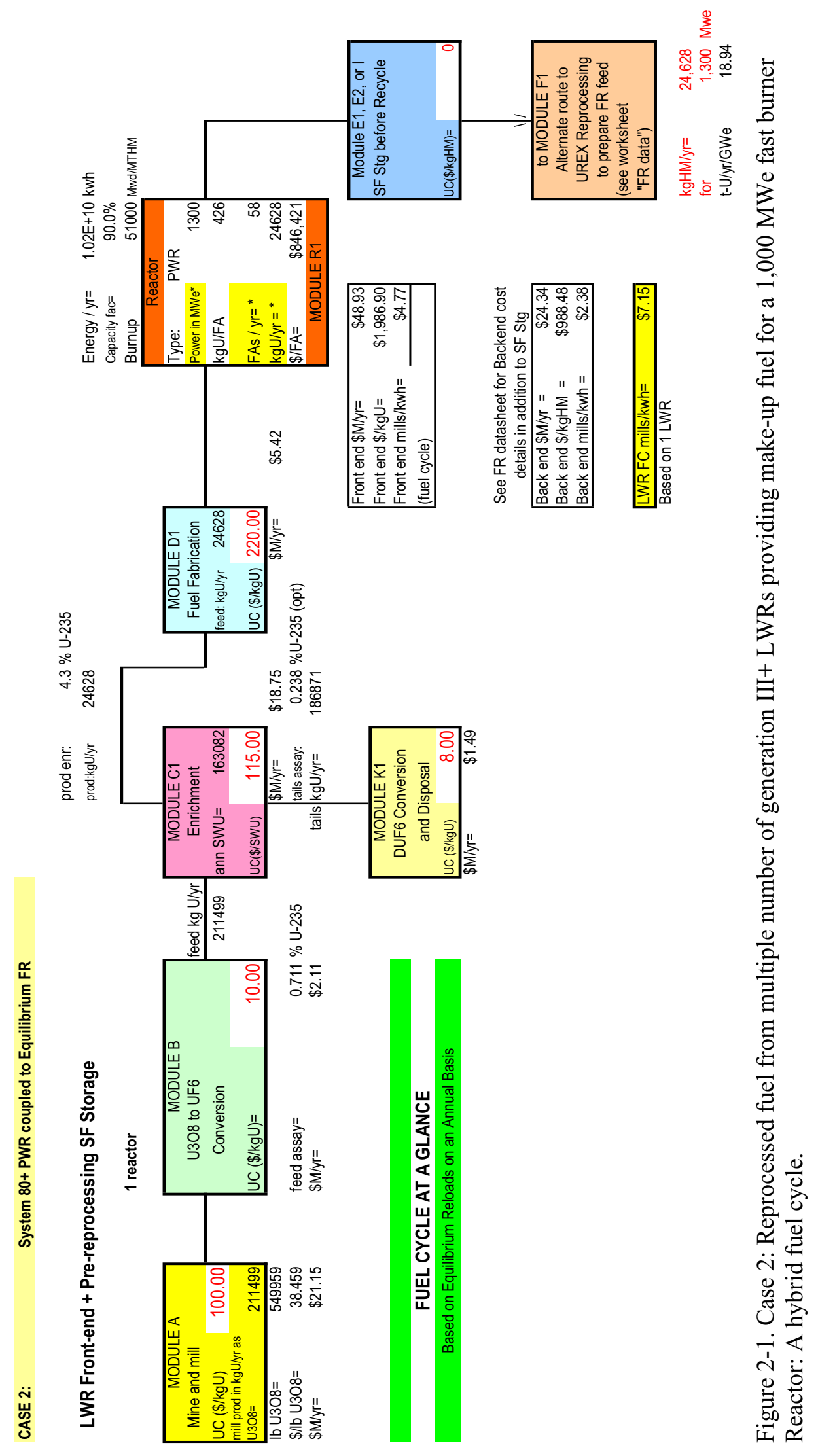




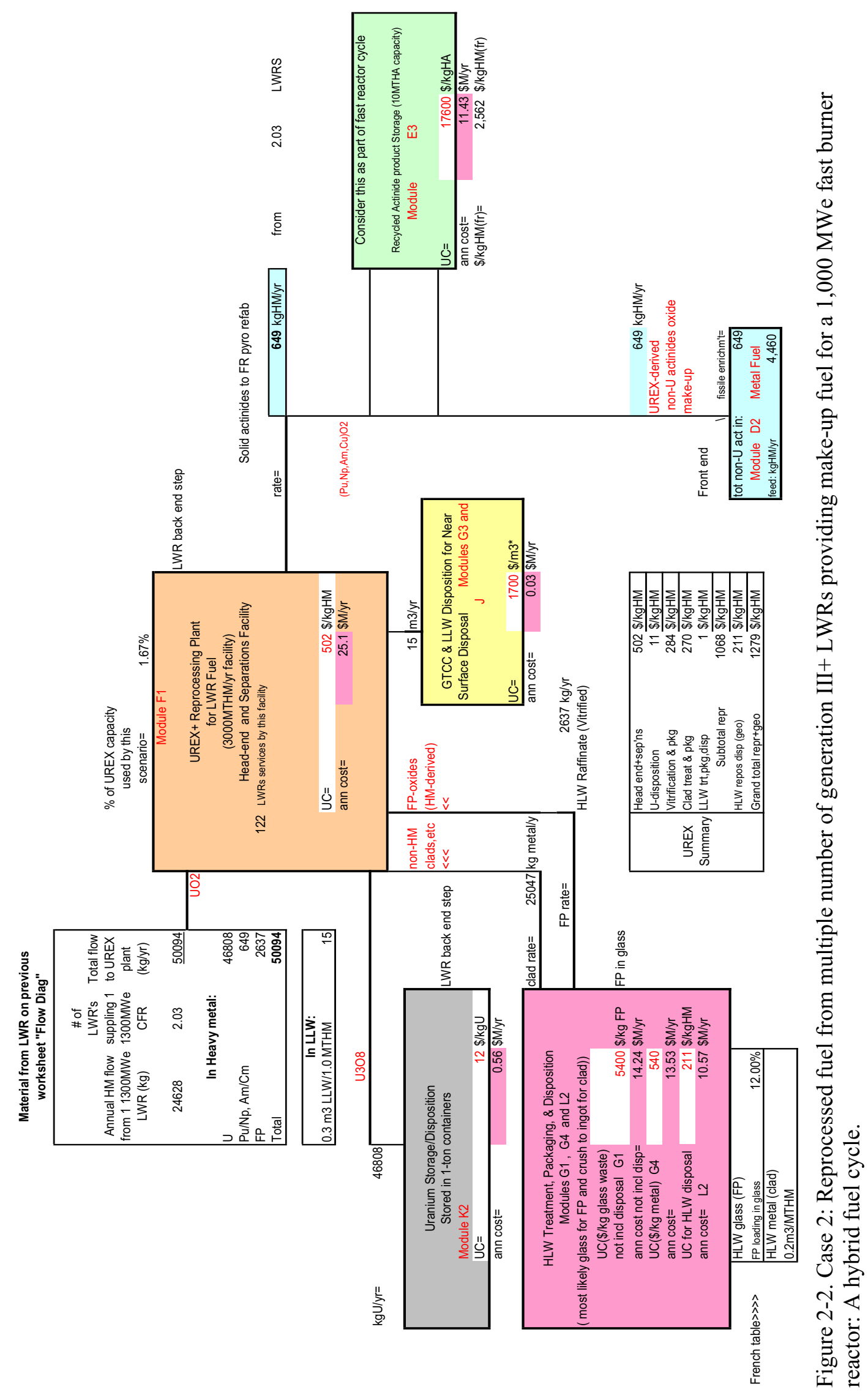




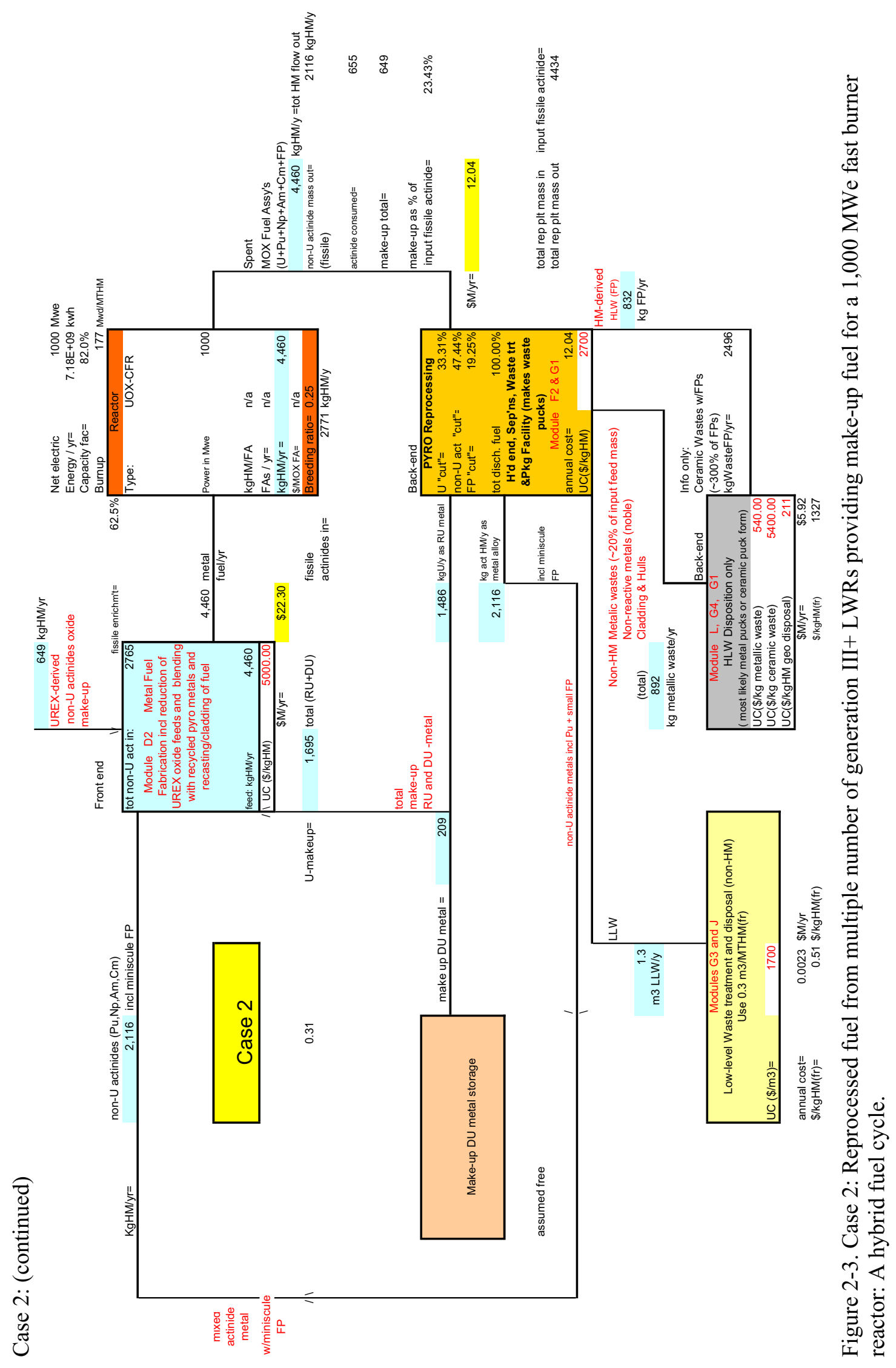


In order to establish an equilibrium system that supports an $\sim 27 \%$ mix by GWe capacity of converter fast reactors (CFRs) to LWRs, an equivalent thermal to fast reactor system was defined. The CFRs were assumed to operate at very high actinide burning rates with a conversion ratio (CR) of 0.25. The CR is defined as the number of fissile atoms produced divided by the number of fissile atoms consumed. In this case, the assumption is that approximately two 1,300 MWe LWRs are operating with the same conditions as Case 1 and have used fuel reprocessed by aqueous UREX+ technology. Furthermore, the separated actinides provide nearly $24 \%$ of the fissile material requirement for an equilibrium fuel cycle for a 1,000 MWe sodium-cooled fast reactor "burner." The fuel cycle cost in mills $/ \mathrm{kW} \mathrm{h}$ is calculated for both the LWRs that are operating on a partially closed cycle, and for the fast reactor which is operating in the burner mode. Also calculated was the properly-weighted "mills/kW h" fuel cycle cost component for the hybrid multiple reactor system as a whole. The reprocessed LWR actinides comprise the make-up stream of fissile material to the fast reactor. The burner fast reactor is collocated with pyrochemical fuel reprocessing in order to continue to recycle DU and actinides for future fast reactor fuel. Fission products are converted into ceramic wastes and metallic pyro wastes are prepared for HLW disposition.

\subsubsection{Case 2: General Assumptions}

Case 2 is the most complex fuel cycle of the four cases evaluated due to the coupling of the LWRs to an aqueous reprocessing back-end, and then a hand-off of the separated and stored LWR actinides to a fast reactor recycle system, which involves pyrochemical recycle and fuel fabrication. The following assumptions are provided to help describe the functionality of this system:

- $\quad$ The front-end fuel cycle material balance and unit cost ranges for each 1,300 MWe LWR are identical to those in Case 1. The assumption was that 2.03 LWRs are required to supply enough fissile material to partially fuel the 1,000 MWe fast reactor burner. This means that approximately $50,000 \mathrm{kgHM} / \mathrm{yr}$ of used fuel from the LWRs is sent to the UREX+ reprocessing plant, Module F1. The LWR used fuel is assumed to have cooled in the LWR used fuel pools for about five years.

- $\quad$ The fast reactor burner is a metal-fueled reactor capable of at least partially burning out the actinides $\mathrm{Pu}, \mathrm{Np}, \mathrm{Am}$, and $\mathrm{Cm}$. The only additional makeup material required is DU metal, from which some $\mathrm{U}-238$ is transmuted to $\mathrm{Pu}-239$ and fissioned.

- Metal fast reactor fuel is assumed to be reprocessed by the pyrochemical method using molten salt chemistry. New metal fuel is cast and clad in the same building which means that the two fuel cycle steps of remote-handled fast reactor fuel reprocessing in Module F2, and remote-handled fast reactor fuel fabrication in Module D2-1 are accomplished in one integrated facility.

- The metal fuel is assumed homogeneous with no separation into drivers and targets/blankets, and is a blended and cast mix of DU, $\mathrm{Pu}, \mathrm{Np}, \mathrm{Am}$, and $\mathrm{Cm}$. Fissile actinide isotopes constitute around $60 \%$ of the fuel mass. A small amount of lanthanide fission product is also carried over into the recast fuel. This also contributes to the need for remote hot-cell fuel fabrication.

- Waste-handling modules are included to deal with the LLW, greater-than class C (GTCC), and HLW coming from the aqueous (UREX+) and pyroprocessing steps. After treatment and packaging, LLW waste is assumed to go to near surface disposal and GTCC or HLW to geologic disposal. 
- $\quad$ Separated reprocessed uranium from the UREX+ process is assumed to be converted to U3O8, packaged, and stored or disposed as LLW as in Module K2. The uranium is not re-enriched or refabricated to reprocessed uranium (REPU) oxide fuel for this scenario.

- $\quad$ Accommodation must be made for the safe and secure storage of actinides as oxides from the UREX+ process as in Module F1. An additional facility, designated as Module E3, is assumed available for this purpose.

\subsubsection{Back-End Modules for the LWRs}

3.2.2.1 Case 2: Module F1 (UREX+ Reprocessing Plant). The UREX+ aqueous reprocessing plant is a large regional facility handling up to 3,000 MTHM annually. This would represent the annual used fuel output of over (120) 1,300 MWe PWRs.

Module F1 of the overall reprocessing system contains the following activities:

- $\quad$ Head-end steps.

- $\quad$ Separation, capture, treatment, and packaging of volatile radioisotope fission products (Kr, $\mathrm{Xe}, \mathrm{I})$.

- $\quad$ Separation of REPU from fission products and higher actinides (HA).

- $\quad$ Separation of fission products from higher actinides $(\mathrm{Pu}, \mathrm{Np}, \mathrm{Am}, \mathrm{Cm})$ and their conversion to fission product oxide powders for storage (Module E3) and eventual introduction into the fast reactor fuel cycle.

- $\quad$ Conversion of uranyl nitrate solution to U3O8, a safe form for REPU storage and disposal.

- Conversion of the mixed actinide solution to an oxide form for storage until pyrochemical fast reactor fuel fabrication facility is ready for it. The assumed Module F1 unit cost should contain only these process components.

HLW fission products and some activated cladding/parts treatment, packaging, and disposal are not part of the Module F1 scope and unit cost. unit cost.

LLW and GTCC waste treatment, packaging, and disposal are not part of the Module F1 scope and 
The average breakdown of the heavy-metal derived content of the used fuel results from burning UOX fuel to 51,000 MWd/MTHM and is presented in mass fraction percentiles in Table 2 below.

Table 2. Mass fraction percentiles from burning UOX fuel.

\begin{tabular}{|l|c|}
\hline Uranium & $93.40 \%$ \\
\hline Plutonium & $0.06 \%$ \\
\hline Neptunium & $1.16 \%$ \\
\hline Americium & $0.06 \%$ \\
\hline Curium & $7.80 \mathrm{E}-03 \%$ \\
\hline Other MA & $1.91 \mathrm{E}-04 \%$ \\
\hline Fission Products & $5.26 \%$ \\
\hline
\end{tabular}

3.2.2.2 Case 2: Module K2 (Uranium Storage/Disposition). Unburned uranium constitutes over $90 \%$ of the mass volume of the used fuel and has an enrichment level close to or slightly above natural uranium at $0.711 \%$. This aqueous-derived uranium is converted to the form of a solid oxide powder (U3O8) which may contain small amounts of fission product technetium and transmutation product U-232, which has strong gamma-emitting daughters. The U-236 radioisotope formed by irradiation is a neutron absorber and was not present in the unirradiated or virgin UO2 fuel. Unless natural uranium prices rise to a high level, contaminants and undesirable products make the reprocessed U3O8 less attractive for re-enrichment and re-fabrication into UOX fuel, thus Module K2 can be invoked to handle its packaging and disposal. It should also be noted that the DU3O8 handled in Module K1, from the LWR fuel cycle enrichment step, is much more benign from a radiation standpoint than the reprocessed U308 handled by Module K2. The assumption was made that both reprocessed U308 and "tails" U3O8 could be poured into steel boxes capable of holding one metric ton of U308/DU308. This is the storage path followed in France for uranium from the LaHague facility and French enrichment plants. The unit cost for the K1 and K2 steps should include acquisition of the boxes and transportation to the warehouse area or to shallow LLW burial.

\subsubsection{Case 2: Module G1 (HLW Waste Conditioning, Storage, and Packaging).}

Separated nonvolatile fission product oxides are dissolved in a borosilicate glass to prevent leaching during repository storage. The glass is then poured into stainless steel cans which represent waste "logs." Multiple logs will ultimately go into a repository waste container. For this case, a $12 \%$ fission product loading, which is the percentage of fission product in the glass waste form, was assumed. Approximately $5 \%$ of the original heavy metal mass, charged enriched uranium became a nonvolatile fission product during reactor irradiation. The unit cost for this vitrification step is expressed in $\$ / \mathrm{kg}$ fission product.

About $20 \%$ of the heavy metal equivalent content is an activated $\mathrm{Zr}$ or $\mathrm{Zr}$ alloy which results from head-end and dissolution operations in the reprocessing plant. These $\mathrm{Zr}$ cladding hulls and other parts are crushed and encased in a can in which the volume of solids is smaller than the log containing the fission products. The crushed $\mathrm{Zr}$ metal volume can be placed in the same repository package as the vitrified logs. The total volume of this repository package should be smaller than that which is required to geologically disposition an equivalent amount of whole used fuel assemblies for an open cycle. The unit cost for disposition of the HLW metal parts is expressed in $\$ / \mathrm{kg}$ metal.

The disposition costs for the fission products and activated metals should include acquisition of the cans enclosing the HLW. The HLW facility is likely to be located immediately adjacent to the head-end and separations areas. 
3.2.2.4 Case 2: Module L2 (HLW Disposition). The cans from Module G1 are placed in a repository waste package somewhat similar to the multi-purpose canisters proposed for whole used fuel assemblies. This package is shipped to the repository for possible repackaging and placement. The cost for this operation can be expressed in terms of $\$ / \mathrm{kgHM}$, where HM represents the original fuel mass from which the fission products were formed. This unit cost in terms of $\$ / \mathrm{kgHM}$ should be considerably lower than that for the disposal of nonreprocessed used fuel assemblies from an open cycle.

\subsubsection{Case 2: Modules G3, G4, and J (LLW and GTCC Waste Conditioning, Storage,} and Packaging, and LLW Disposal). Associated with the processing of $50,000 \mathrm{kgHM} / \mathrm{yr}$ in the UREX+ plant, is the production of LLW and GTCC waste. Module G3 represents the facility which treats and packages the LLW, which is mostly rags, paper suits, contaminated tools and trash, etc. Module G4 represents the facility which treats and packages the GTCC waste. This facility can include activated metals and more highly contaminated trash. Module $\mathrm{J}$ is for near surface or shallow burial of the packaged waste at private licensed or government facilities such as Envirocare or the Nevada Test Site (NTS). For this scenario, it was assumed that the waste of interest is LLW produced at the rate of $0.3 \mathrm{~m} 3$ per MTHM from Module F1. The unit cost is expressed as \$/m3 LLW and includes a component for treatment that is about one-third of the total and the remaining two-thirds is disposal. The cost of the disposal boxes is included in the treatment cost.

The seven fuel cycle steps described above constitute the "back-end" steps for the LWR component of this hybrid case. The same seven "back-end" fuel cycle steps can be associated with the fast reactor operating in both an actinide burning and electricity production mode as will be described below.

3.2.2.6 Case 2: Module R2 (Fast Reactor). Fuel cycle material balance data was obtained for a 1,000 MWe fast burner reactor envisioned by the Argonne National Laboratory (ANL) and Idaho National Laboratory (INL). The annual fuel charge rate to the reactor is the starting point for calculating the throughput requirements for the other fuel cycle steps of fuel fabrication, pyrochemical fuel reprocessing, and use of make-up fissile actinides from UREX+ reprocessing.

The following base attributes define the reactor for Case 2: Module R2:

NOTE: All quantities are expressed on an annualized basis regardless of fuel cycle length.

- $\quad$ Power capacity of $1,000 \mathrm{MWe}$ (net).

- A capacity factor of $82 \%$.

- $\quad$ Converter fast reactor operating at a CR of 0.25 .

- $\quad$ Thermodynamic efficiency of the reactor is $\sim 42 \%$ (based on Japanese Sodium-cooled Fast Reactor [JSFR]).

- $\quad$ Annual electricity production of 7,180 million kilowatt-hours.

- $\quad$ An average fuel burnup of 177,000 MWd/MTHM.

- $\quad$ U-Pu-Np-Am-Cm-Zr metal alloy stainless steel-clad, sodium-bonded cast fuel at an average reload enrichment of $\sim 60 \%$ fissile actinide isotopes.

- A reactor operating life of 40 years. 
- A total annual enriched HM requirement of 4,460 $\mathrm{kgHM}$ per yr. This latter value is the basis for determining the annual throughput requirement for all other fuel cycle steps.

- $\quad$ All metal fuel assemblies are assumed identical in isotopic content and mass for purposes of model simplification with no segregation of drivers and targets.

- Reactor annual operations costs include LLW disposal of wastes such as paper, rags, resins, contaminated equipment, etc.

- $\quad$ Reactor-generated LLW disposal costs are not included in the fuel cycle cost as per usual utility industry practice.

- $\quad$ Approximately $24 \%$ of the reactor fissile material charge comes from UREX+ LWR actinide product. The rest is available from recycled unburned fissile and plutonium isotopes formed by neutron absorption by the U-238 in the DU make-up and recycle.

\subsubsection{Front-end Cycle Steps for the Fast Reactor}

\subsubsection{Case 2: Module E3 (Recycled Actinide Product Storage). The UREX-derived} higher actinide oxides produced in Module F1 must be safely and securely stored in a government facility until the fast reactor fuel fabrication facility, Module D2, is ready. Assuming that this facility will have space for $100 \mathrm{MT}$ of HM at any given time, the unit cost for storage is on a $\$ / \mathrm{kgHM}$ actinide emplaced/removed per year basis and assumes the same throughput as the amount of HA produced annually from UREX+ or $649 \mathrm{kgHM}$ higher actinides per year. Amortization of the facility capital cost of $\$ 600 \mathrm{M}$ and annual operational costs are factored into the unit cost. This facility is likely to be located adjacent to Module D2, the fast reactor fuel fabrication facility.

\subsubsection{Case 2: Module D2-1 (Metal Fuel Fabrication). This very complex facility is} supplemental, but integral to Module F2, the pyrochemical fast reactor fuel recycle facility, Module E3, the LWR actinide storage facility, and should be collocated with these facilities for security and radiochemical safety reasons. This fabrication facility must perform the following operations:

- $\quad$ Convert the actinide oxides from Module E3 to metal for blending, most likely by thermochemical reduction or other special pyrometallurgical process.

- $\quad$ Convert whatever forms the make-up DU is (UO2, U3O8, UF6, etc) to a metal form for blending. Due to the large inventory of legacy U-238 available, the make-up DU is considered to be supplied to this program at no cost. A Module K1-type facility could supply oxide feed.

- $\quad$ Receive the recycled uranium and HA metals from Module F2 and blend these with the make-up DU metal, make-up LWR actinide metals, and any alloying metal such as zirconium.

- $\quad$ Cast the metal alloy into fuel rods.

- $\quad$ Clad the rods in stainless steel and provide the necessary internal sodium bonding.

- $\quad$ Bundle the rods into fast reactor fuel assemblies. 
All of these operations must be done in a hot-cell or remote handling environment because of the presence of fission product impurities, the radiation from Am and $\mathrm{Cm}$ decay reactions, and spontaneous and neutron generation from some HA radionuclides. The cost for these operations is expressed in the usual $\$ / \mathrm{kgHM}$ unit cost figure of merit for fuel fabrication. Because of the complexity of this remote-handled fuel fabrication operation, the unit cost will be much larger than for conventional LWR UOX or uranium, Pu-only MOX fuel, which can be contact handled.

\subsubsection{Back-End Modules for the Converter Fast Reactor (CFR)}

3.2.4.1 Case 2: Module F2 (Pyrochemical Reprocessing). The metal and salt based pyrochemical fuel recycle plant is likely to be a small facility (tens of $1,000 \mathrm{~s}$ of $\mathrm{kg} / \mathrm{yr}$ annually) handling the fuel from several nearby CFRs, perhaps in a "Nuclear Fuel Cycle Park" type arrangement. A smaller plant size may be feasible due to the batch nature of the pyrochemical process and the very high fissile content of the fuel. Small physical geometries may be needed to avoid criticality concerns and necessitate multiple equipment trains, additional facility footprint, and operations support.

Module F2 of the overall pyrochemical reprocessing system contains the following activities:

- $\quad$ Head-end steps including decladding and sodium bond removal

- $\quad$ Separation, capture, treatment, and packaging of volatile radioisotope fission products $(\mathrm{Kr}, \mathrm{Xe}, \mathrm{I})$

- $\quad$ Separation of most fission products from the actinides (U, $\mathrm{Pu}, \mathrm{Np}, \mathrm{Am}, \mathrm{Cm}$ )

- $\quad$ Regeneration of process salts and electrochemical components where possible.

Short term storage of the recycle alloy form until Module D2; the pyrochemical fast reactor blending/fuel fabrication facility is ready to take the separated product streams.

HLW fission products and some activated cladding/parts treatment, packaging, and disposal are not part of the Module F2 scope and unit cost. These are explained in Sections 3.2.4.2 and 3.2.4.3.

LLW and GTCC waste treatment is explained in Section 3.2.4.4.

The average breakdown of the heavy-metal derived content of the fast reactor used fuel results from the burning of converter fast reactor fuel to $177,000 \mathrm{MWd} / \mathrm{MTHM}$ and is presented in mass fraction percentile, following in Table 3:

Table 3. Mass fraction percentiles from burning converter fast reactor fuel.

\begin{tabular}{|l|r|}
\hline Uranium & $33.3 \%$ \\
\hline Neptunium & $0.95 \%$ \\
\hline Plutonium & $38.63 \%$ \\
\hline Americium & $5.86 \%$ \\
\hline Curium & $1.95 \%$ \\
\hline Other HA & $0.02 \%$ \\
\hline Fission products & $19.24 \%$ \\
\hline
\end{tabular}


3.2.4.2 Case 2: Module G1 (HLW Treatment, Packaging, and Disposition). Separated nonvolatile fast reactor fission product forms are dissolved in a ceramic puck to prevent leaching during repository storage. The pucks are placed into long, cylindrical, stainless steel cans which represent waste "logs." Multiple cans will ultimately go into a repository waste container. The "fission product loading" is the percent of the puck mass which is fission product (FP). For this case, $25 \%$ is assumed, for example, the puck "filler ceramic" mass is $300 \%$ of the FP mass. The unit cost for this ceramification step is expressed in $\$ / \mathrm{kg}$ total ceramic product. Approximately $18 \%$ of the original heavy metal or total actinide mass becomes a nonvolatile fission product during reactor irradiation. About $20 \%$ of the heavy metal equivalent content is activated stainless steel, or SS alloy, that results from head-end and decladding operations in the reprocessing plant. These cladding hulls and other parts are crushed and encased in a can. The volume of solids in this can is smaller than the can containing the fission product ceramic pucks. The crushed SS metal volume can be placed in the same repository package as the ceramified logs. The waste conditioning of the cladding hulls is significantly easier than ceramification. If the hulls can be washed to LLW standards, the disposition costs will become less.

The total volume of this repository package should be somewhat smaller than that required to geologically disposition an equivalent amount of whole used fast reactor fuel assemblies from an open cycle. The unit cost for dispositioning HLW SS metal parts is expressed in $\$ / \mathrm{kg}$ metal. Both unit costs should include acquisition of the cans enclosing the HLW pucks. Most likely, the pryro dedicated HLW facility will be located immediately adjacent to the head-end and separations areas of Module F2.

There was not enough information available to consider disposition of salt wastes from pyroprocessing. The extent to which these salts can be regenerated is not known. The same can be said for the zirconium, which is used to alloy the actinide metals in the fuel.

3.2.4.3 Case 2: Module L2 (HLW Disposition). The cans from Module G1 are placed in a repository waste package somewhat similar to the multi-purpose package proposed for whole used LWR fuel assemblies. This package is shipped to the repository for possible repackaging and placement. The cost for this operation can be expressed in terms of $\$ / \mathrm{kgHM}$, where HM represents the original fuel mass from which the fission products were formed. This unit cost in terms of $\$ / \mathrm{kgHM}$ should be considerably lower than that for the disposal of FR used fuel from an open cycle.

\subsubsection{Case 2: Modules G3, G4, and J (LLW and GTCC Treatment, Packaging, and}

Disposal). Associated with the processing of $4460 \mathrm{kgHM} / \mathrm{yr}$ in the pyrochemical fuel recycle plant is the production of LLW and GTCC waste. Module G3 represents the facility which treats and packages the LLW, which is mostly rags, paper suits, contaminated tool and trash, etc. Module G4 represents the facility which treats and packages the GTCC waste, which can include activated metals and more highly contaminated trash. Module $\mathrm{J}$ is for near surface or shallow burial of the packaged waste at private licensed or government facilities such as Envirocare or NTS. For this scenario the assumption was that the waste of interest is LLW produced at the rate of $0.3 \mathrm{~m}^{3}$ per MTHM from Module F2. The unit cost is expressed as $\$ / \mathrm{m}^{3} \mathrm{LLW}$, which includes a component for treatment of about one-third of the total. The disposal comprises the remaining two-thirds. The cost of the disposal boxes is included in the treatment cost.

These six fuel cycle steps constitute the "back-end" steps for the CFR component of this hybrid case. By proper weighting and summing the fuel cycle component annual costs, a "mills/ $\mathrm{kW}$ h" cost for this hybrid fuel cycle can be calculated. 


\subsection{Case 3: A Generation IV Sodium-cooled Fast Reactor Operating on a Closed Pyrochemical Fuel Cycle}

For this case a 1,000 MWe Fast Reactor operates on a totally closed fuel cycle with only DU required for make-up. All of the actinides, including uranium are recycled. 


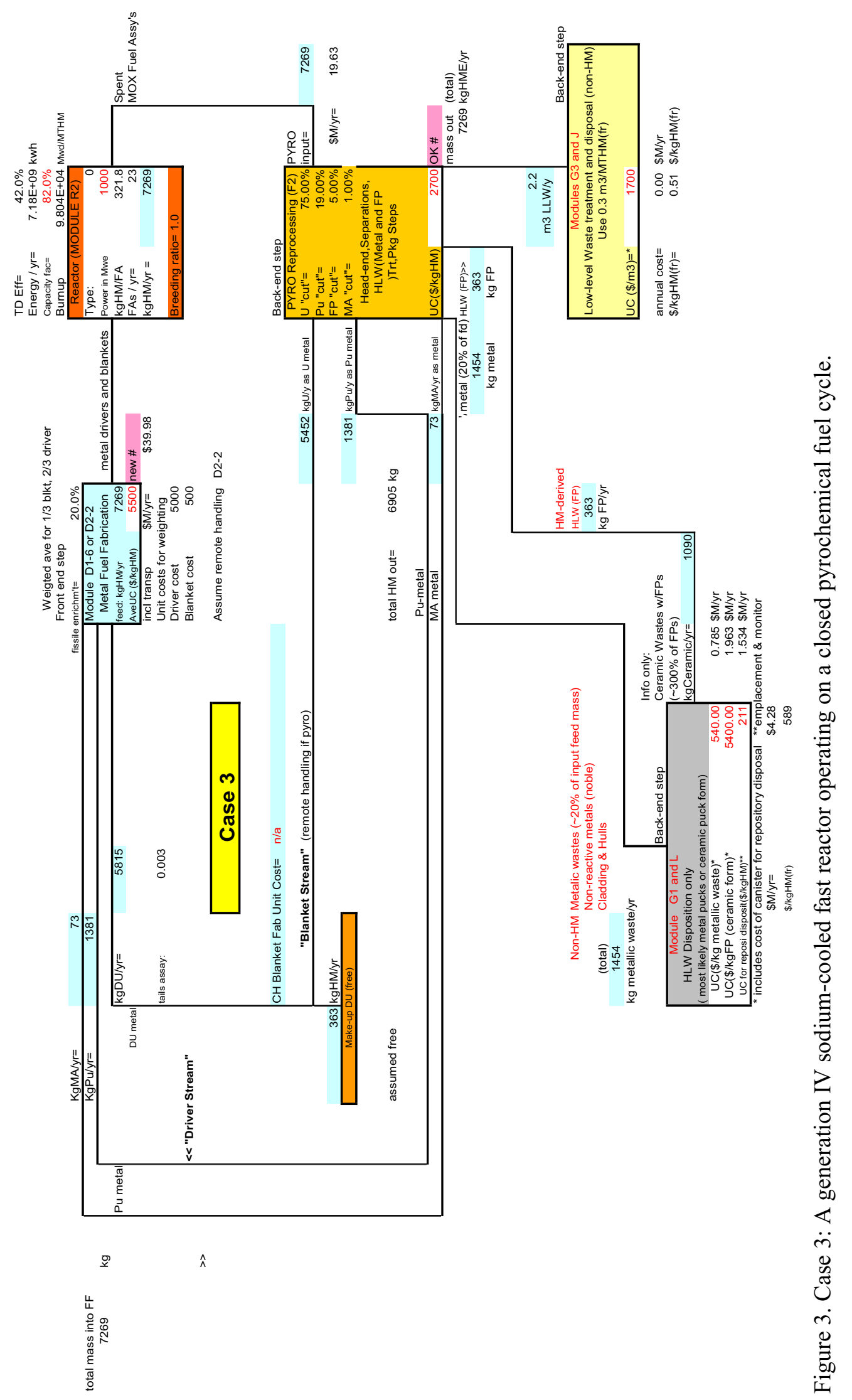


The following base attributes define the fast reactor for Case 3: A Generation IV Sodium-cooled Fast Reactor Operating on a Closed Pyrochemical Fuel Cycle:

NOTE: All quantities are expressed on an annualized basis regardless of fuel cycle length.

- $\quad$ Reactor is a scale down from the 1430 MWe JSFR design. Material balance is based on a scale down to 1,000 MWe.

- $\quad$ Reactor operates on metal rather than mixed-oxide fuel. The JSFR concept is an MOX-based fuel.

- $\quad$ Reprocessing is pyrochemical based rather than aqueous based.

- $\quad$ Has a power capacity of 1,000 MWe (net).

- $\quad$ Thermodynamic efficiency of the reactor is $\sim 42 \%$ based on JSFR.

- A capacity factor of $82 \%$.

- $\quad$ Fast reactor operating at a breeding ratio of 1.0.

- $\quad$ The annual electricity production is 7,180 million kilowatt-hours.

- $\quad$ Has an average fuel burnup of 107,600 MWd/MTHM.

- $\quad$ U-Pu-Np-Am-Cm-Zr metal alloy stainless steel-clad, sodium-bonded cast fuel at an average reload enrichment of $\sim 20 \%$ fissile actinide isotopes in HM.

- $\quad$ The reactor operating life is 40 years.

- A total annual HM requirement of 7,270 $\mathrm{kg} \mathrm{HM} / \mathrm{yr}$. This latter value is the basis for determining the annual throughput requirement for all other fuel cycle steps.

- $\quad$ For purposes of modeling, all metal fuel assemblies are assumed identical in fissile/isotopic content and mass. In reality for the JSFR system, the fuel would be segregated into drivers and blankets/targets.

- $\quad$ Reactor annual operations costs include LLW disposal of wastes such as paper, rags, resins, contaminated equipment, etc. Reactor LLW disposal costs are not included in the fuel cycle cost as per usual utility industry practice.

- Approximately 5\% of the reactor nuclear material charged is makeup DU. DU replaces the fissile isotopes which have been converted to fission products and much of the DU is converted to fissile $\mathrm{Pu}-239$. DU is assumed available at no cost.

- $\quad$ Used fuel derived actinides are recycled quickly back to the reactor. Reprocessing takes place as soon as the fuel is cool enough to be safely handled in the pyrochemical facility. 


\subsubsection{Case 3: Module D2 (Metal Fuel Fabrication) Assumptions}

Fuel fabrication is the only "front-end" module for this fuel cycle. This very complex facility is integral to Module F2, the pyrochemical fast reactor fuel recycle facility and should be collocated for security and radiochemical safety reasons. This fabrication facility must perform the following operations:

- $\quad$ Convert whatever forms the make-up DU is in (UO2, U3O8, UF6, etc) to a metal form for blending. The make-up DU form is considered to be supplied to this program at no cost. A Module K1-type facility could supply this feed.

- $\quad$ Receive the recycled uranium and HA metals from Module F2 and blend these metals with the make-up DU metal and any alloying metal such as zirconium.

- $\quad$ Cast the metal alloy into fuel and blanket/target rods.

- $\quad$ Clad the rods in stainless steel and provide the necessary internal sodium bonding.

- $\quad$ Bundle the rods into fast reactor fuel assemblies.

All of these operations must be done in a hot-cell or remote handling environment because of the presence of fission product impurities, radiation from $\mathrm{Am}$ and $\mathrm{Cm}$ decay reactions, and spontaneous neutron generation from some HA radionuclides . In addition, there are also special processes for handling the reactive sodium metal used in the fuel-cladding bonding. The cost for these operations is expressed in the usual $\$ / \mathrm{kgHM}$ unit cost figure of merit for fuel fabrication and should represent a weighted average of unit costs for driver fuel production and blanket/target production. Because of the complexity of this remote-handled fuel fabrication operation, the unit cost will be significantly larger than for conventional LWR UOX or Pu-only MOX fuel which can be contact handled.

\subsubsection{Back-End Modules for the CFR}

3.3.2.1 Case 3: Module F2 (Pyrochemical Reprocessing). The metal and salt based pyrochemical fuel recycle plant is likely to be a small facility (tens of $1,000 \mathrm{~s}$ of $\mathrm{kg} / \mathrm{yr}$ annually) handling the fuel from several nearby CFRs, perhaps in a "Nuclear Fuel Cycle Park" type arrangement. This smaller plant size is made feasible because of the batch nature of the pyrochemical process and the very high fissile content of the fuel associated with criticality concerns. The overall pyrochemical reprocessing system for Module F2 contains the following activities:

- $\quad$ Head-end steps including decladding and sodium bond removal.

- $\quad$ Separation, capture, treatment, and packaging of volatile radioisotope fission products (Kr, Xe, I).

- $\quad$ Separation of most fission products from the actinides (U, Pu, Np, Am, Cm).

- $\quad$ Regeneration of process salts and electrochemical components where possible. 
- Short term storage of the recycle alloy form until the pyrochemical fast reactor blending/fuel fabrication facility Module D2 is ready for it. The assumed Module F2 unit cost should contain only these bulleted process components.

- $\quad$ HLW fission products and some activated cladding/parts treatment, packaging and disposal are not part of the Module F2 scope and unit cost and are discussed in Section 3.3.2.2.

- $\quad$ LLW and GTCC waste treatment, packaging, and disposal are not part of the Module F2 scope and unit cost and are discussed in Section 3.3.2.4.

- $\quad$ The breakdown of the heavy-metal derived content of the fast reactor used fuel results from the burning of fast reactor fuel to $107,600 \mathrm{MWd} / \mathrm{MTHM}$ and in mass fraction percentile is presented in Table 4 below. The fuel average includes both the blanket/target and driver used fuel components.

Table 4. Mass fraction percentiles from burning fast reactor fuel.

\begin{tabular}{|l|r|}
\hline Uranium & $75 \%$ \\
\hline Plutonium & $19 \%$ \\
\hline Minor Actinides & $1 \%$ \\
\hline Fission products & $5 \%$ \\
\hline
\end{tabular}

3.3.2.2 Case 3: Module G1 (HLW Treatment and Disposition). This description is the same as for Module G1 in Case 2 (see Section 3.2.4.2).

3.3.2.3 Case 3: Module L2 (HLW Disposition). This description is the same as for Module L in Case 2 (see Section 3.2.4.3).

3.3.2.4 Case 3: Modules G3, G4, and J (HLW, GTCC Treatment, Packaging, and LLW Disposal). This description is the same as for Modules G3, G4, and J in Case 2, except that the heavy metal throughput upon which the waste quantities are derived is somewhat larger (see Section 3.2.4.4).

\subsection{Case 4: Thermal Recycle of DU, Pu, Np MOX drivers and EU, Am, Cm MOX targets in a Generation III+ LWR}

See Figure 4 below for Case 4: Thermal Recycle of DU, Pu, Np MOX drivers and EU, Am, and Cm MOX targets in a Generation III+ LWR. 


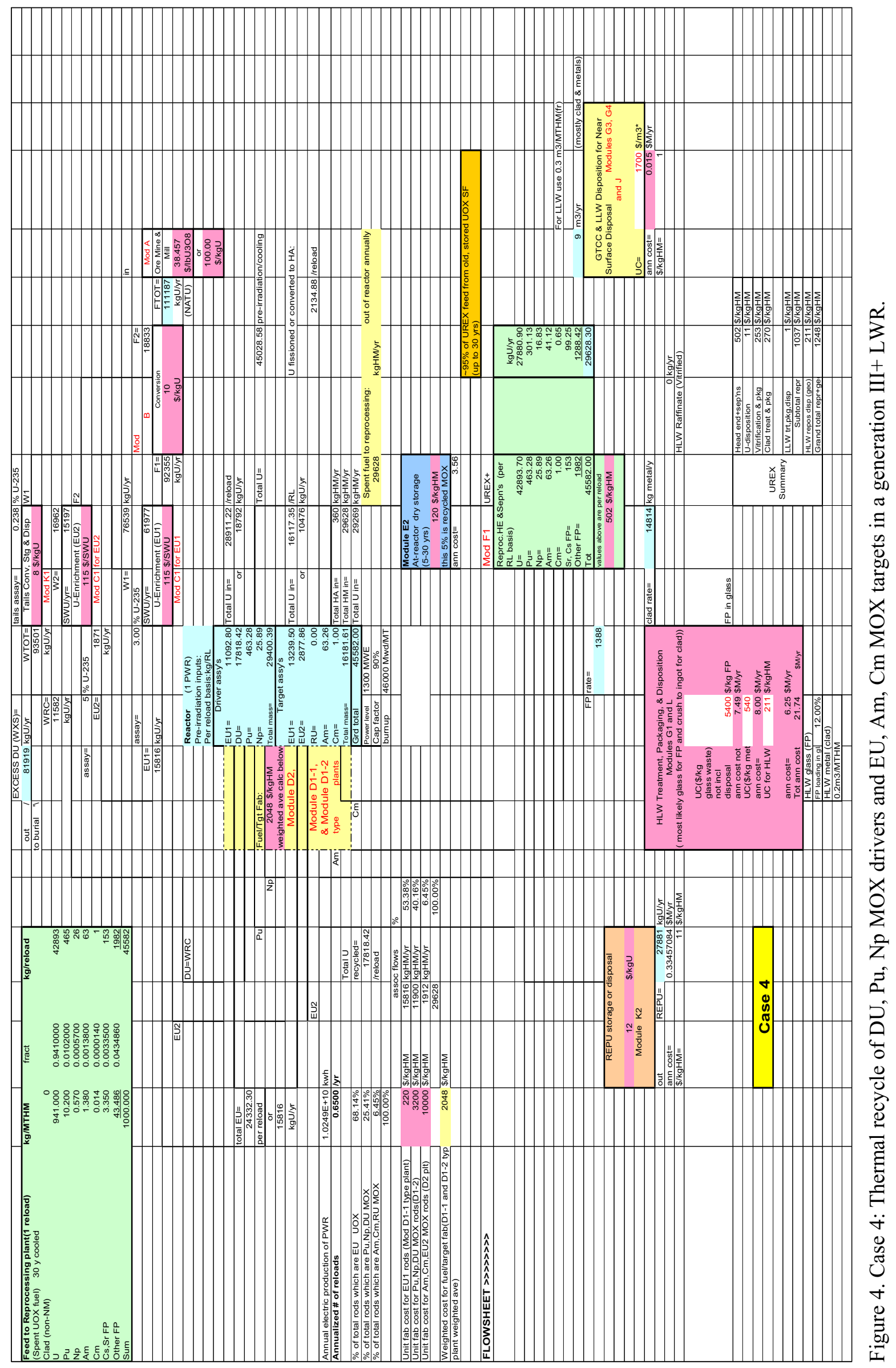




\subsubsection{Case 4: General Assumptions}

Old ( $\sim 30 \mathrm{yr})$ or "legacy" used LWR nuclear fuel has significant higher actinide (Am, Cm) radioisotopes that present a heat load problem for long term repository placement. The thermal spectrum of an LWR is capable of transmuting some of these radionuclides to shorter-lived radioisotopes. In this scenario, the assumption was that a UREX +3 reprocessing process is applied to mostly (95\%) LWR UOX legacy fuel and the partial UOX/MOX used fuel (5\%) from the reactor's own fuel cycle. The separated $\mathrm{Pu}, \mathrm{Np}$ and $\mathrm{Am}, \mathrm{Cm}$ streams are mixed with UOX and are made into MOX drivers and targets respectively for re-insertion. The MOX rods constitute approximately one-quarter MOX PWR core, and the remaining rods are typical PWR enriched UOX fuel.

This fuel cycle is complex for several reasons:

- $\quad$ Three types of fuel rods need to be acquired, all coming from different kinds of fuel fabrication facilities: Module D1, contact-handled; and D2, remote-handled, type facilities.

- $\quad$ Two assays of enriched uranium are needed; 3\% U-235 for normal UOX rods, and 5\% U-235 constituent for the $\mathrm{Am}, \mathrm{Cu}$ target rods.

- $\quad$ The UREX+3 (Module F1) aqueous reprocessing plant must handle both legacy PWR UOX used fuel (95\%), and the cooled UOX and MOX used fuel from the two types of assemblies.

- Some of the uranium enrichment tails can be diverted for use as a diluent for the Pu, Np MOX rods.

- $\quad$ The reprocessed uranium is not re-used for fuel, and must be packaged and stored.

\subsubsection{Case 4: Module R1 (Reactor)}

A basic uranium fuel cycle material balance was available for the ABB System $80+$ PWR reactor, and was modified by Oak Ridge National Laboratory (ORNL) reactor physicists to handle the special transuranic rod types. The definition of reactor rod elemental charge rates is used as the starting point for calculating the throughput requirements for the other fuel cycle steps of ore mining and milling, yellowcake to UF6 conversion, uranium enrichment, fuel fabrication, used fuel reprocessing, and treatment, packaging, or disposal of all wastes.

The following base attributes define the reactor for Case 4: Module R1:

NOTE: All quantities are expressed on an annualized basis regardless of fuel cycle length.

- $\quad$ Power capacity of $1,300 \mathrm{MWe}($ net)

- $\quad$ A capacity factor of $90 \%$

- Annual electricity production of 10,200 million kilowatt-hours

- $\quad$ An average fuel burnup of 46,000 MWd/MTHM

- A fuel cycle length time between refuelings of 1.54 years 
- The thermodynamic efficiency of the reactor is $34.0 \%$

- A reactor operating life of 40 yrs.

The reactor annual total HM requirement is $29,269 \mathrm{kgHM} / \mathrm{yr}$ and this requirement is met using two types of PWR fuel assemblies:

- Driver assemblies consisting of two types of fuel rods: 3\% U-235 enriched UOX rods, and 4.2\% $(\mathrm{Pu}, \mathrm{Np}) \mathrm{O} 2$ in DUO2 MOX rods. The UOX rods can be purchased commercially and the $\mathrm{Pu}, \mathrm{Np}$ MOX rods can be produced in a glovebox type MOX fuel fabrication facility.

- $\quad$ Target assemblies consist of two types of fuel rods: 3\% U-235 UOX, and 2.1\% (Am, Cm) O2 in EUO2 MOX rods. The enriched uranium constituent is enriched to 5\% U-235. All UOX rods can be purchased commercially; however, the mixed higher-actinide target rods will need to be produced in a highly shielded hot-cell type fabrication facility.

Reactor annual operations costs include LLW disposal of reactor-related wastes such as paper, rags, resins, contaminated equipment, etc. Reactor-related LLW disposal costs are not included in the fuel cycle cost.

\subsubsection{Front-end Fuel Cycle Steps for Case 4}

3.4.3.1 Case 4: Modules A, B, C1, and K1 (Mining and Milling, Conversion, Enrichment, and DUF6 Conversion and Disposal). The comments for these steps are the same as for Case 1 . The quantities of services or materials required for Case 4 are less than for Case 1 because many UOX rods are displaced by MOX rods for which these services are not required. Because two different U-235 assays are required, two enrichment facility Module $\mathrm{C} 1$ blocks are shown. In reality, both enrichments would be available from the same enrichment plant.

3.4.3.2 Case 4: Modules D1-1, D1-2, and D2 (CH and RH Fuel Fabrication). Because of the three different types of rods, this step is the most complex and expensive in the fuel cycle. Over half the fuel rods are typical PWR UOX fuel and can be made in Module D1-1, a commercial facility, at relatively low unit cost. For purposes of this evaluation, it is assumed that $(\mathrm{Pu}, \mathrm{Np}) \mathrm{O} 2 \mathrm{MOX}$ driver rods can be fabricated in facilities requiring only glovebox operations.

Module D1-2 represents a glovebox facility similar to the $\mathrm{PuO} 2 \mathrm{MOX}$ plants now operating in Europe. The (Am, Cm) O2 target rods will need to be manufactured in a remote-handling hot-cell environment more like that envisioned for re-fabricating pyrochemically reprocessed fuels such as Module D2. The rods will also need to be bundled into a fuel assembly in a remote-handling environment. Transportation of the assemblies to the reactor is also included in this step. A unit cost for fuel fabrication can be calculated by throughput weighting the unit costs for the three fuel types.

\subsubsection{Back-end Fuel Cycle Steps for Case 4}

3.4.4.1 Case 4: Module E2 (Reactor Dry Storage). Legacy used fuel from older reactor pools will need to be stored and queued for eventual recycling. Concrete casks can be purchased and the appropriate site security provided. This cost can be expressed on a $\$ / \mathrm{kgHM}$ basis.

3.4.4.2 Case 4: Module F1 (Aqueous Reprocessing). The UREX plant is a large regional facility and handles up to 3,000 MTHM annually. This would represent the annual used fuel output of over (120) 1,300 MWe PWRs. 
Module F1 of the overall reprocessing system contains the following activities:

- Head-end steps.

- $\quad$ Separation, capture, treatment, and packaging of volatile radioisotope fission products $\mathrm{Kr}, \mathrm{Xe}, \mathrm{I}$.

- $\quad$ Separation of uranium from fission products and higher actinides.

- $\quad$ Separation of fission products from higher actinides $\mathrm{Pu}, \mathrm{Np}, \mathrm{Am}, \mathrm{Cm}$, and separation of the actinides into $\mathrm{Pu}, \mathrm{Np}$ and $\mathrm{Am}, \mathrm{Cm}$ streams.

- $\quad$ Conversion of uranyl nitrate solution to U3O8, a safe form for REPU storage and disposal.

- Conversion of the mixed actinide solutions to an oxide form for storage until the Module D1-2 and D2 fuel fabrication facilities are ready. The assumed Module F1 unit cost should contain only these process components.

HLW (fission products and some activated cladding/parts) treatment, packaging and disposal are not part of the Module F1 scope and unit cost. These costs are considered separately in Sections 3.4.4.3 through 3.4.4.5.

LLW and GTCC waste treatment, packaging, and disposal are not part of the Module F1 scope and unit cost. These costs are considered separately in Section 3.4.4.6.

The breakdown of the heavy-metal derived content of the UOX legacy and MOX used fuel is shown in mass fraction percentile in Table 5, and constitutes the feed to the UREX+ plant:

Table 5. Mass fraction percentiles from burned UOX and MOX used fuel.

\begin{tabular}{|l|c|}
\hline Uranium & $94.10 \%$ \\
\hline Plutonium & $1.02 \%$ \\
\hline Neptunium & $0.06 \%$ \\
\hline Americium & $0.14 \%$ \\
\hline Curium & $0.0014 \%$ \\
\hline Fission Products & $4.69 \%$ \\
\hline
\end{tabular}

3.4.4.3 Case 4: Module K2 (REPU Storage or Disposal). Comments on this step are the same as for Case 2 (see Section 3.2.2.2).

3.4.4.4 Case 4: Module G1 (HLW Conditioning). Separated nonvolatile fission product oxides are dissolved in a borosilicate glass to prevent leaching during repository storage. The glass is then poured into stainless steel cans which represent waste "logs." Multiple logs will ultimately go into a repository waste container. For this case, $12 \%$ of the "fission product loading," which is the fission product from the glass mass, is assumed. The unit cost for this vitrification step is expressed in $\$ / \mathrm{kg}$ fission product. Approximately 5\% of the original HM enriched uranium and HA mass becomes nonvolatile fission product during reactor irradiation. About $20 \%$ of the HM equivalent content is activated $\mathrm{Zr}$ or $\mathrm{Zr}$ alloy, which results from head-end and dissolution operations in the reprocessing plant. These cladding hulls and other parts are crushed and encased in a can in which the volume of solids is smaller than the log containing the fission products. The crushed $\mathrm{Zr}$ metal volume can be placed in the 
same repository package as the vitrified logs. The total volume of this repository package should be smaller than that required to geologically disposition an equivalent amount of whole fuel assemblies. The unit cost for dispositioning HLW Zr metal parts is expressed in $\$ / \mathrm{kg}$ metal. Both unit costs should include acquisition of the cans enclosing the HLW. The HLW facility is likely be located immediately adjacent to the head-end and separations areas.

3.4.4.5 Case 4: Module L2 (HLW Disposition). Same comments as for Case 2 (see Section 3.2.2.4).

\subsubsection{Case 4: Modules G3, G4, and J (LLW GTCC Treatment, Packaging, and}

Disposal). Associated with the processing of $29,600 \mathrm{kgHM} / \mathrm{yr}$ in the UREX+ plant is the production of LLW and GTCC waste. Module G3 represents the facility which treats and packages the LLW, which is mostly rags, paper suits, contaminated tool and trash, etc. Module G4 represents the facility which treats and packages the GTCC waste, which can include activated metals and more highly contaminated trash. Module $\mathrm{J}$ is for near surface or shallow burial of the packaged waste at privately licensed or government facilities such as Envirocare or NTS.

For this scenario, it was assumed that the waste of interest is LLW produced at the rate of $0.3 \mathrm{~m}^{3}$ per MTHM from Module F1. The unit cost is expressed as $\$ / \mathrm{m}^{3} \mathrm{LLW}$ and includes a component for treatment of about one-third of the total, and disposal constitutes the remaining two-thirds. The cost of the disposal boxes is included in the treatment cost. 


\section{FUEL CYCLE COST BASIS AND DATA UNCERTAINTY RANGES}

Table 6 describes the front-end and back-end fuel cycle cost modules used in the four cases and the associated cost distributions. The nominal values are based on selected cost data developed for the 2006 AFC Cost Basis report and data obtained from studies completed since the release of the report in July 2006. An uncertainty cost range was defined for the 20 main cost modules. Low and high values were based on historical or study data determined by the judgment of the cost analyst. Since the cost data was intended to be a projection of costs $15+$ years into the future, assumptions were made about general nuclear growth in the United States and internationally.

A discussion on the general basis and selection of the costs shown in Table 6 are provided below for the primary cost contributors. Additional details on the cost basis are available in the 2006 AFC Cost Basis report, and a summary of the fuel cycle costs used in this analysis are provided in Appendix A.

Table 6. Fuel cycle module cost uncertainty.

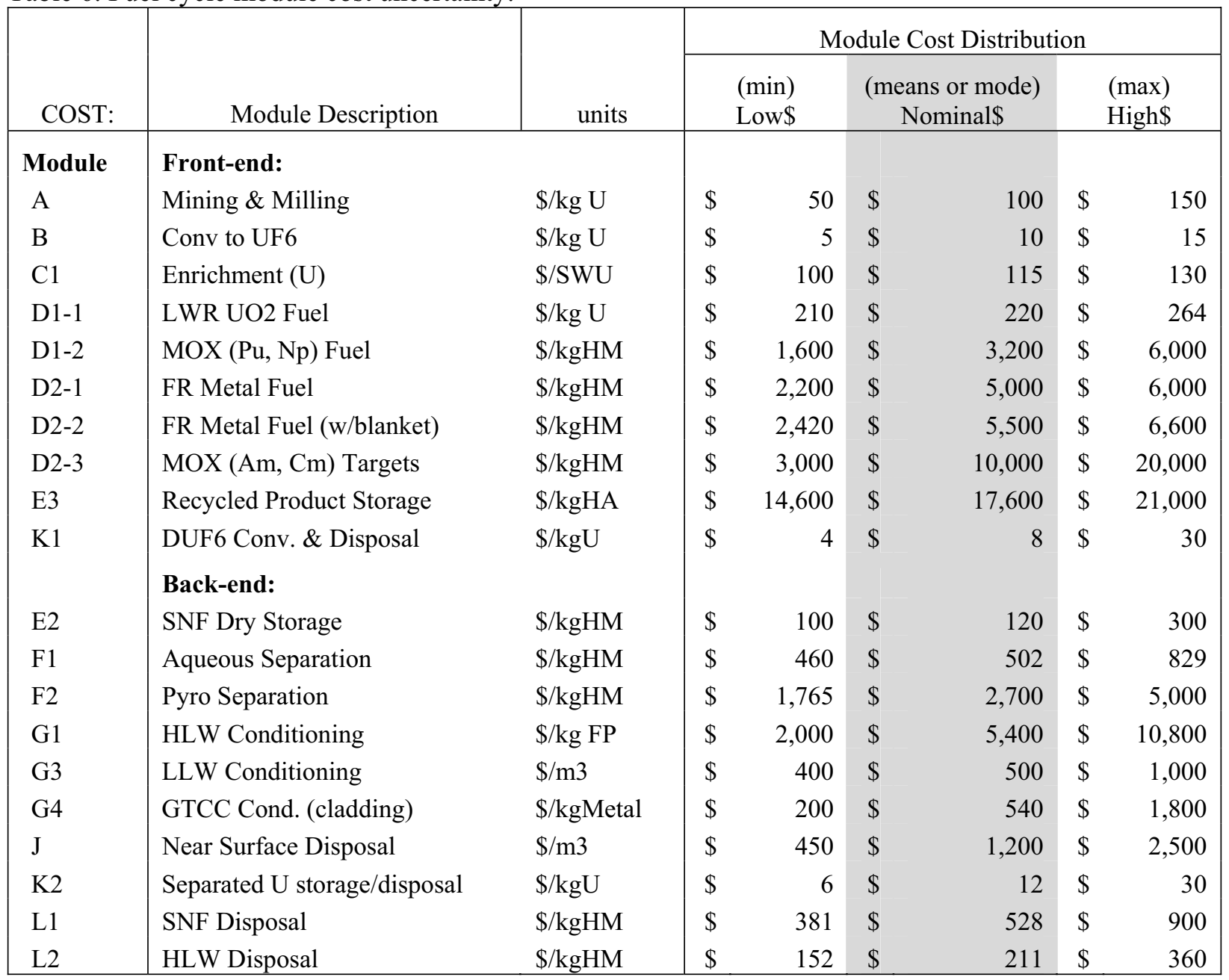




\subsection{Cost Assumptions on Fuel Cycle Front-End}

A summary of the fuel cycle costs, the flow basis for costing and the annual module (nominal based) costs used in this analysis are provided in Appendix A. The following sections provide the technical and cost assumptions used to apply the front-end fuel cycle costs for the cases.

Modules $A, B$-Uranium prices are based on future long term contracts in the range of $\$ 50-\$ 150 / \mathrm{kg} \mathrm{U} 308$ based on historical price levels (\$20-\$50/kg U308) and with consideration to current spot market prices $(\$ 60 / \mathrm{lb}$ or $\sim \$ 132 / \mathrm{kg} \mathrm{U308)}$ ). Conversion prices reflect a competitive and mature market at a world capacity of 58,000 MTU/yr. Conversion is currently around $\$ 12.00 / \mathrm{kgU}$, as UF6, and costs are not expected to grow substantially in the future. Low end costs reflect a case where secondary supplies remain plentiful and early exploration determines increased sources of low cost to recover uranium ore bodies. High end costs are based on the scenario in which nuclear power grows quickly and exceeds the pace at which new reserves can be developed or forces the use of reserves that are more costly to mine.

Module C1, K1-Enrichment services are a competitive and mature market where current world demand and supply are nearly matched. SWU spot prices in the U.S. have held in the $\$ 105$ to $\$ 120 /$ SWU range over the past five years; however, the range recently has risen to $\$ 134 /$ SWU. SWU prices are not likely to be reduced in the future due to expected fairly tight supply and demand constraints. At the high end, if demand for uranium increases rapidly, capacity would also have to increase and that would increase the price to approximately $\$ 130 /$ SWU. DUF6 conversion/disposal is expected to be fairly stable (range of $\$ 4$ to $\$ 30 / \mathrm{kgU}$ ) due to technology improvements, but may run into regulatory difficulties with DU3O8 disposition.

Module D1-1 - LWR fuel assembly cost ranges on the upper end are reflective of potential higher enrichments ( $>5 \%$ U-235), and higher burn-ups in the future. Claddings capable of burn-ups greater than $60,000 \mathrm{MWd} / \mathrm{MTHM}$ will be considerably more expensive. There is also a cost penalty for utilizing fuel made from REPU, a practice which introduces impurity and health physics concerns into the fabrication process. Low end costs for this service would reflect a weak market in a highly competitive industry.

\subsection{Cost Assumptions Regarding Separations and Refabrication of Fuels}

A summary of the fuel cycle costs, the flow basis for, and annual module (nominal based) costs used in this analysis are provided in Appendix A. The following section provides the technical and cost assumptions used to apply the separation and refabrication of fuel costs on the cases.

Module F1-Nominal cost estimates for aqueous reprocessing, which is around $\$ 500 / \mathrm{Kg}$, are based on assumptions of high economies of scale at 3,000 MT/year, using $\sim 80 \%$, and technical optimization for a U.S. plant. Significant knowledge on separation has been gained by the French and will be developed by the Japanese before any commercial facility is operated in the U.S. Higher end costs are based on a more conservative Organization for Economic Cooperation and Development (OECD) analysis, and lower end costs are based on optimistic assumptions which regard continuous processing, low end process storage requirements, and secondary waste disposition. This analysis is accounted for in the G modules. 
Module F2-Pyrochemical processing costs are expected to be more expensive than aqueous reprocessing due to smaller scale facilities and technology uncertainties. Design studies for integrated fast reactor plus used fuel processing facilities indicate a nominal cost around $\$ 2,700 / \mathrm{kgHM}$. On the high end, costs could increase as the process proceeds to higher deployment level and more stringent safety requirements for a larger facility, in the scale of $\$ 5,000 / \mathrm{kgHM}$. Low end costs were based on potential technology breakthroughs and economies of scale which could cut the high end costs to $\$ 1,650 / \mathrm{kgHM}$.

Module D1-2 - For contact-handled LWR MOX fuel compared to what is produced in the United Kingdom and France, Module D1-2 can be constantly handled and implies that fission product impurities and HA (Am, Cm, Cf) impurities are sufficiently low enough that glovebox handling is possible. This module can readily handle $\mathrm{Pu}$ and $\mathrm{Np}$ MOX fuels. The unit cost range is very wide since the range depends on the following factors: fabrication plant size, the extent to which the plant has been amortized, batch size for the reload order, powder and fuel quality requirements, non-Pu-239 plutonium isotope content, and market factors to some degree.

Module D2-1-This module is for "homogeneous" metal fast reactor fuel where only one type of fuel assembly is manufactured. There is no segregation of "drivers," "blankets," or "targets." For many fast reactor concepts, such fuel would be a $\mathrm{Pu}, \mathrm{U}, \mathrm{Zr}$ alloy. This type of fuel has the lowest cost range in the $\mathrm{D} 2$ series since the fabrication line only deals with one type of product.

Module D2-2 - This module is the composite unit cost for heterogeneous fuel where "drivers" and "blankets" are separated, which means the production of at least two fuel products and increased plant complexity and costs. The starting "blanket" material might be inexpensive DU metal; however, this metal still needs to be blended and handled in a remote "hot-cell" type facility.

Module D2-3 - This module specifically handles the cost of producing higher actinide or select fission product LWR or fast reactor "target" rods in a remote handling, hot-cell type environment. The cost range is significantly higher for several reasons: difficult handling of highly radioactive materials, small batch size relative to "drivers" and "blankets," complications of blending exotic metals, and more difficulty in maintaining product uniformity and quality.

\subsection{Cost Assumptions on Fuel Cycle Back-End}

A summary of the fuel cycle costs, the flow basis for costing, and annual module (nominal based) costs used in this analysis are provided in Appendix A. The following section provides the technical and cost assumptions used to apply the fuel cycle back-end costs on the cases.

Modules G1, G3, G4, J-Waste conditioning is based on using vitrified glass waste forms for HLW. Costs for vitrification are expected to become lower in the future, resulting from the knowledge gained in defense wastes vitrification. The high costs for canisters, which are estimated at over $\$ 1 \mathrm{M}$ per canister may be reduced by $50 \%$ through high production quantities. Waste loading may be maximized in the glass with a nominal loading of $12 \%$. The low $\$$ case is based on higher future loadings of up to $60 \%$ $\mathrm{wt} \%$. LLW nominal cost data is based on general LLW noncombustible debris treated and disposed at commercially competitive rates. High end costs are representative of LLW contaminated with the Resource Conservation and Recovery Act (RCRA) (42 U.S.C. 6901) regulated waste products. GTCC metal disposition is based on a 10:1 cost improvement over HLW conditioning and packaging, due to greater waste packaging densities and use of less expensive waste packages.

Module L1 - Current used fuel disposal costs range from current baseline charges of one mill $/ \mathrm{kW} \mathrm{h}$ (equivalent to $\sim \$ 381 / \mathrm{kg} \mathrm{HM}$ ) to cost projections of $\$ 63 \mathrm{~B}$ for $70,000 \mathrm{MT}$ ( $\$ 900 / \mathrm{kg} \mathrm{HM}$ (DOE 2001). A nominal cost of $\$ 428 / \mathrm{kg} \mathrm{HM}$ is based on $\sim \$ 68.6 \mathrm{~B}$ for a repository expanded to the technical limit 
of 129,000 MTHM. However, the Electric Power Research Institute (EPRI) has indicated that potentially much higher capacities may be attainable (2006). Ceramic and metal waste forms would need to be approved for direct disposal in the repository. The costs resulting from changes to the NWPA were not addressed in this study. Senator Domenici's bill, S.2589, seeks to accelerate and ensure the opening of the Yucca Mountain repository with reforms intended to minimize roadblocks threatening progress. If approved, the law could remove the current capacity bases and change the utility fee structure for disposal of HLW/SNF in the geologic repository.

Module L2 - The nominal estimate in this study is $\$ 211 / \mathrm{kgHM}$ based on a $250 \%$ disposal efficiency of that for used fuel, as a function of the unit costs in Module L1. This efficiency assumes that the LWR fuel is discharged at an average burnup of $50,000 \mathrm{MWd} / \mathrm{kgHM}$. This is $12 \%$ fission product loading and placement of 1 MT HLW in the same space as 1 MT SNF. These costs are in general agreement with the Harvard study (Bunn et al. 2003), which used a central estimate of $\$ 200 / \mathrm{kgHM}$ for HLW disposal.

\subsection{Cost Sensitivity Analysis}

The cost sensitivity analysis was developed using the DPL tool to evaluate cost distributions based on the assigned probability conditions. In this analysis, three types of simulations were performed:

1. Monte Carlo simulation using a normal distribution. This was centered on the nominal module cost with a standard deviation equal to $\pm 50 \%$ of the nominal unit cost.

2. Monte Carlo simulation with a triangular distribution, where specific data points were assigned for the absolute low value, most likely (nominal) value, and the absolute high value for each module.

3. Discrete simulation with a three point normal distribution generated from probabilities for the low, nominal, and high costs. Using this type of distribution, a cumulative risk profile can be developed as shown in Figure 5. The graph shows that the total fuel cycle costs could range from $\sim 5$ to $21 \mathrm{mills} / \mathrm{kW}$ h. The most interesting result is for Case 3, which shows in the lower cost range to be less expensive than Cases 1 or 2 . Also, the discontinuity between 6 to 8 mills $/ \mathrm{kW} \mathrm{h}$ is the result of using a $25 \%$ probability of achieving low fast reactor metal fabrication and pyro separations costs. Case 4 is clearly the most expensive fuel cycle, due to large flows to expensive fuel fabrication operations.

The Monte Carlo simulation using a normal distribution was also run using continuous chance nodes. In this simulation, the values of the module costs were centered at the nominal value with a standard deviation of plus or minus $50 \%$ of the nominal value. The model was run over 1 million samples to obtain the smoothed profile as shown in the frequency risk profile shown in Figure 6.

The Monte Carlo simulation maintains the same basic result as the cumulative risk profile, which was based on discrete values of low, nominal, and high. The Case 1 (red color) results in a higher probability than Case 2 (green) of achieving lower fuel cycle costs in the range of about one to five mills $/ \mathrm{kW} \mathrm{h}$. However, the distribution is very broad and indicates an overlap of costs of greater than $50 \%$. Case 1 has a slightly wider overall distribution than Case 2, due to higher capacity demands for mining \& milling, enrichment, fuel fabrication, and geologic disposal; all of which have large cost uncertainties. Case 3 also shows the significant uncertainty including low values similar to Cases 1 and 2, but the distribution also extends beyond the high ranges of Cases 1 and 2, and reaches to almost 18 mills. Case 4 is clearly the highest cost option, with a range stretching from 5 mills to over 19 mills. 


\section{Cumulative Risk Profile}

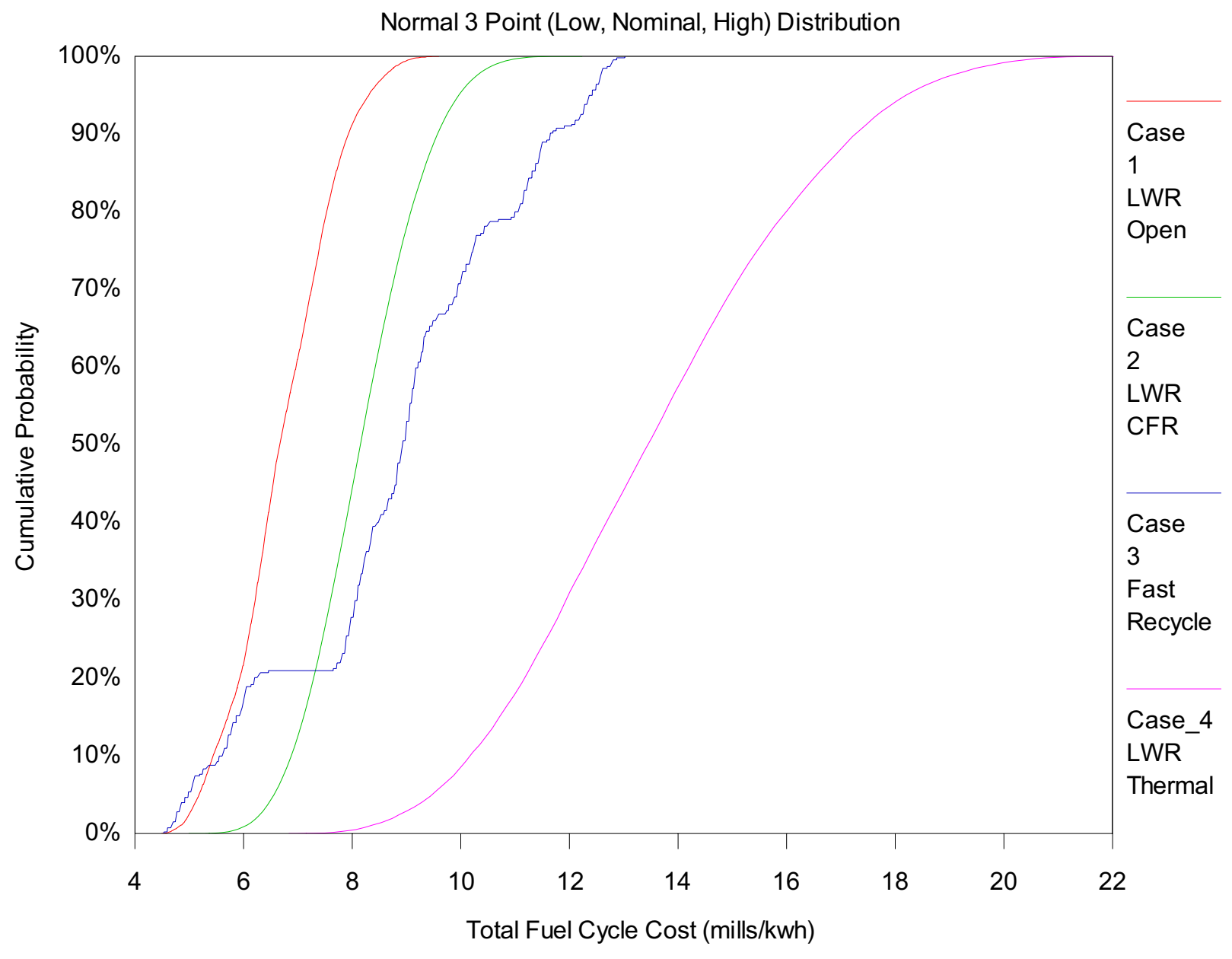

Figure 5. Cumulative risk profile using 3 point data and normal distribution. 


\section{Frequency Risk Profile}

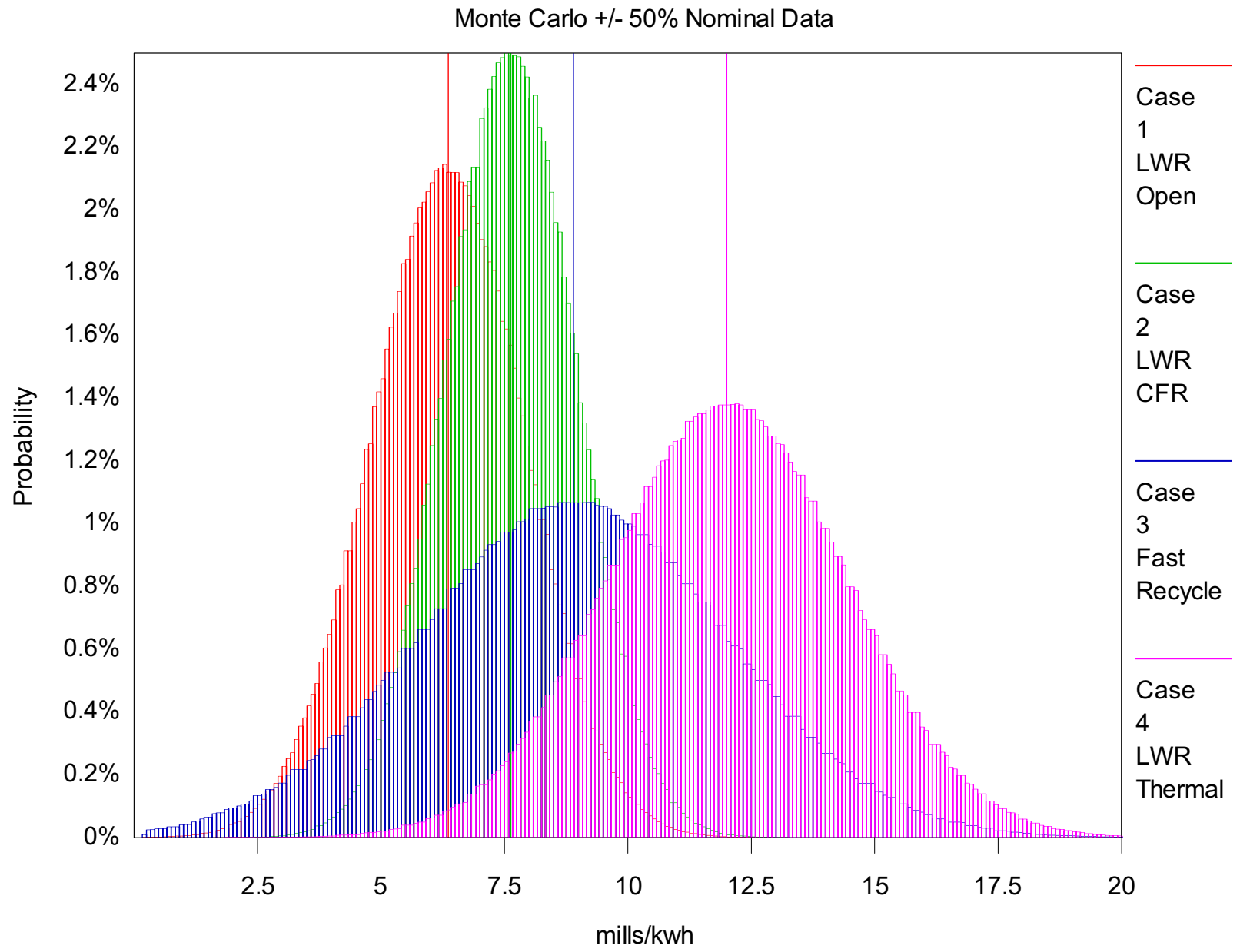

Figure 6. Frequency risk profile using Monte Carlo Analysis at $\pm 50 \%$ nominal data.

As mentioned previously in the general cost assumptions, a conservative approach was taken using existing conventional practices to define key parameters in this study (for example, waste form, operational efficiencies, etc.). In actual practice, with additional design, development, and operational experience, streamlined processes and technologies would be deployed to increase efficiencies and minimize costs. Alternative strategies are potentially available within each of the four strategy areas that have the potential to reduce costs (for example, thermal recycle using inert matrix fuels).

Figure 7 provides a frequency risk profile using a triangular distribution based on the low (minimum), high (maximum), and nominal (mode) data. The triangular distribution corresponds closely with the plus or minus two standard deviations of the normal distribution using the three point data. 


\section{Frequency Risk Profile}

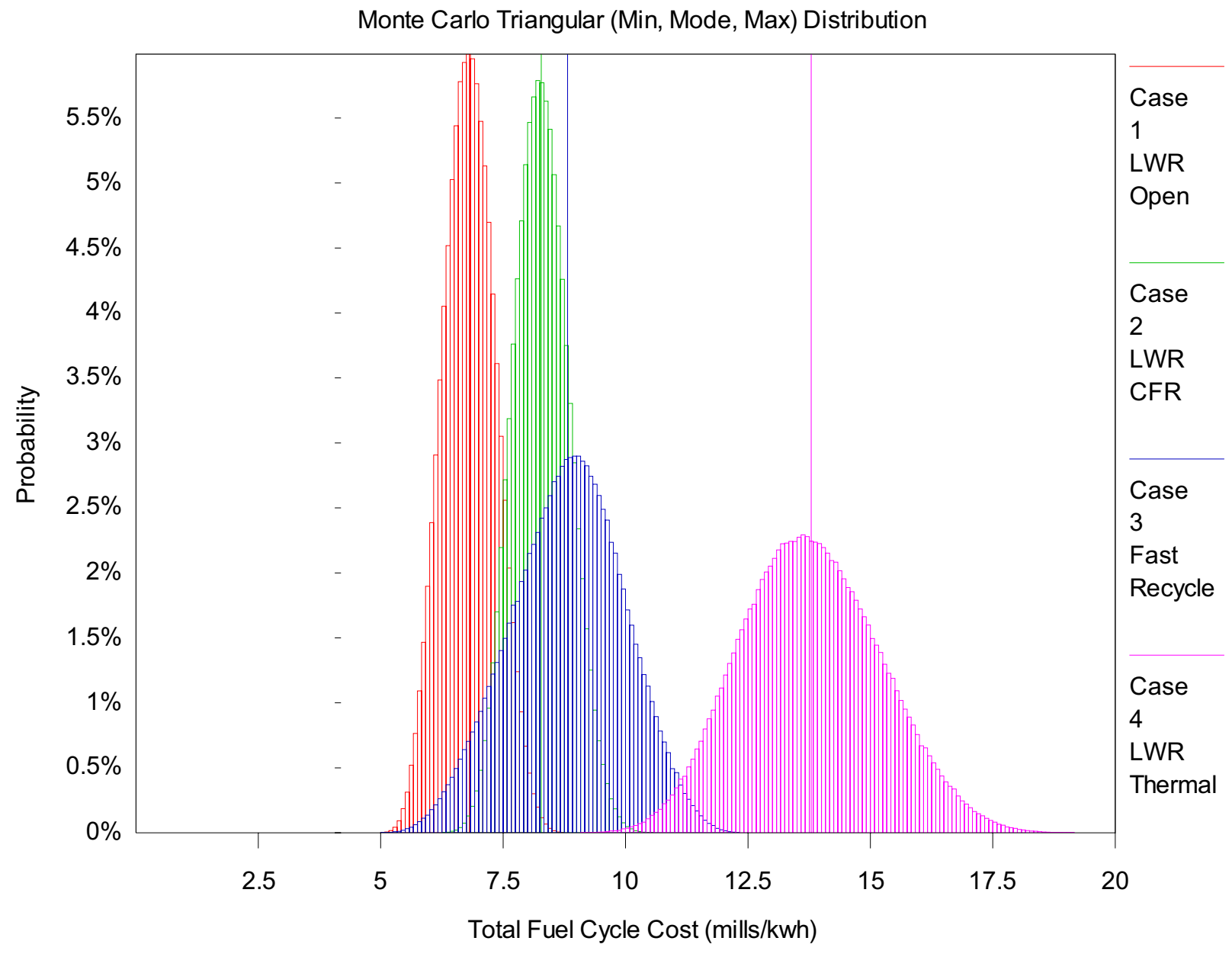

Figure 7. Frequency risk profile using Monte Carlo triangular distribution.

Tables 7 and 8 provide the statistical results that describe the distributions of the four cases. A range of statistical data was produced using the cost distribution curves produced by DPL and then using an Excel spreadsheet to perform data analysis using the descriptive statistics function. At the bottom of each table is a summary of the cost range for each of the four cases. The ranges reflect the values equivalent to plus and minus two standard deviations from the expected value/central value (EV/CE) values. This provides a $95 \%$ uncertainty bounds for each of the cases performed for the AFCI Comparison Report.

Table 7 provides the statistical data for the Monte Carlo Analysis using $\pm 50 \%$ nominal data. The $\mathrm{EV}$, also known as the $\mathrm{CE}$, is very close to the mean of the distribution and reflects a distribution of costs centered on the nominal values shown in Table 6. This distribution produces from 1.5 to 3.7 times the range of cost uncertainty than the distribution using low, nominal, and high data in a normal distribution. 
Table 7. Statistical data for the Monte Carlo Analysis using $\pm 50 \%$ nominal data.

\begin{tabular}{|c|c|c|c|}
\hline $\begin{array}{c}\text { Complete once-through } \\
\text { fuel cycle }\end{array}$ & $\begin{array}{c}\text { Sustained thermal/fast } \\
\text { recycling }\end{array}$ & Sustained fast reactor recycling & Recycling in thermal reactors \\
\hline
\end{tabular}

\begin{tabular}{|c|c|c|c|c|}
\hline & \multicolumn{4}{|c|}{ "Monte Carlo Analysis +/- 50\% Nominal Data (mills/kWh) } \\
\hline & Case_1_LWR_Open & Case_2_LWR_CFR & Case_3_Fast_Recycle & Case_4_LWR_Thermal \\
\hline EV / CE value & 6.36 & 7.63 & 8.90 & 12.01 \\
\hline Mean & 6.35 & 7.70 & 8.97 & 12.07 \\
\hline Standard Error & 0.40 & 0.35 & 0.81 & 0.62 \\
\hline Median & 6.41 & 7.75 & 8.63 & 12.26 \\
\hline Standard Deviation & 3.99 & 3.52 & 8.14 & 6.24 \\
\hline Sample Variance & 15.95 & 12.41 & 66.28 & 38.98 \\
\hline Kurtosis & -1.06 & -1.11 & -1.08 & -1.13 \\
\hline Skewness & -0.03 & 0.00 & 0.10 & -0.06 \\
\hline Range & 15.37 & 12.87 & 30.57 & 23.07 \\
\hline Minimum & -1.27 & 1.32 & -5.32 & 0.09 \\
\hline Maximum & 14.10 & 14.19 & 25.25 & 23.16 \\
\hline Sum & 634.65 & 770.22 & 896.68 & 1206.65 \\
\hline Count & 100.00 & 100.00 & 100.00 & 100.00 \\
\hline Confidence Level(95.0\%) & 0.79 & 0.70 & 1.62 & 1.24 \\
\hline Low (95\%) & 2.4 & 4.1 & 0.8 & 5.8 \\
\hline EV / CE value & 6.36 & 7.63 & 8.90 & 12.01 \\
\hline High (95\%) & 10.4 & 11.2 & 17.0 & 18.2 \\
\hline
\end{tabular}

Table 8 provides the statistical data for the analysis using low, nominal, and high data is a normal distribution. In this analysis, the distribution is biased lower or higher than the mean value, based on the low and high cost values and their probability of occurrence. In this analysis, the EV/CE values for Cases 1,2 , and 4 are higher by 0.3 mills to 1.6 mills than those shown in Table 7 . Case 3 differed by less than 0.1 mill for both analysis.

Table 8. Statistical data for analysis using low, nominal, high data in normal distribution.

\begin{tabular}{|c|c|c|c|c|}
\hline & $\begin{array}{l}\text { Complete once-through } \\
\text { fuel cycle } \\
\end{array}$ & $\begin{array}{l}\text { Sustained thermal/fast } \\
\text { recycling }\end{array}$ & Sustained fast reactor recycling & Recycling in thermal reactors \\
\hline & \multicolumn{4}{|c|}{ Cost Sensitivity Analysis with low, nominal, and high (mills/kWh) } \\
\hline & Case_1_LWR_Open & Case_2_LWR_CFR & Case_3_Fast_Recycle & Case_4_LWR_Thermal \\
\hline V/CE value & 6.72 & 8.19 & 8.82 & 13.59 \\
\hline ean & 6.87 & 8.47 & 8.95 & 14.42 \\
\hline tandard Error & 0.14 & 0.20 & 0.25 & 0.44 \\
\hline edian & 6.85 & 8.48 & 9.13 & 14.51 \\
\hline tandard Deviation & 1.40 & 2.05 & 2.50 & 4.40 \\
\hline ample Variance & 1.95 & 4.20 & 6.25 & 19.34 \\
\hline urtosis & -1.09 & -1.18 & -1.08 & -1.14 \\
\hline Skewness & 0.09 & 0.07 & -0.20 & 0.07 \\
\hline Range & 5.08 & 7.10 & 8.49 & 15.44 \\
\hline inimum & 4.50 & 5.06 & 4.53 & 6.93 \\
\hline aximum & 9.58 & 12.16 & 13.02 & 22.37 \\
\hline m & 686.85 & 847.38 & 895.15 & 1441.83 \\
\hline ount & 100.00 & 100.00 & 100.00 & 100.00 \\
\hline Confidence Level(95.0\%) & 0.28 & 0.41 & 0.50 & 0.87 \\
\hline -ow (95\%) & 5.3 & 6.1 & 6.3 & 9.2 \\
\hline EV / CE value & 6.72 & 8.19 & 8.82 & 13.59 \\
\hline High (95\%) & 8.1 & 10.2 & 11.3 & 18.0 \\
\hline
\end{tabular}

As noted in the beginning of the report, a cost analysis was conducted earlier in fiscal year FY-06 for the 2006 AFCI Comparison Report. These cost ranges were developed from a cost sensitivity analysis using the low, nominal, and high cost data. The resulting cost distribution was trimmed to plus or minus two standard deviations on each side of the expected value to arrive at a $95 \%$ confidence interval. Table 7 
shows a comparison of the cost and ranges from the comparison report to the latest statistical data are compiled in Table 8 for the AFC Economic Sensitivity Analysis. Table 9 shows a comparison of fuel cycle cost ranges from the comparison report to the current study.

Table 9. Comparison of fuel cycle cost ranges from the Comparison Report to the current study.

\begin{tabular}{|l|r|r|r|r|}
\hline & \multicolumn{1}{|c|}{ Case 1 } & \multicolumn{1}{c|}{ Case 2 } & \multicolumn{1}{c|}{ Case 3 } & \multicolumn{1}{c|}{ Case 4 } \\
\hline 2006 Comparison Report (mills/kW h) & 4.3 to 6.2 & 4.4 to 6.5 & 4.9 to 7.7 & 6.7 to 10.8 \\
AFC Econ Sensitivity Analysis (mills/kW h) & 5.3 to 8.1 & 6.1 to 10.2 & 6.3 to 11.3 & 9.2 to 18.0 \\
\hline Cost Delta (mills/kW h) between EVs & -1.5 & -2.7 & -2.4 & -5.2 \\
\hline
\end{tabular}

The updated analysis shows a consistent trend of cost increases over the four cases for the following reasons:

- $\quad$ Front-end costs were updated to reflect higher future market conditions for uranium supplies and nuclear fuels.

- $\quad$ New G modules with improved cost data were developed to better account for the costs of waste conditioning and packaging of the streams originating in reprocessing.

- $\quad$ New cost data were used to analyze costs. These data were not available for the earlier analysis.

- $\quad$ Additional details on the recycling Cases 2, 3, and 4 revealed the need to increase the costs for remote handled fuels in Modules D2-1, D2-2, and D2-3.

The following seven charts illustrate the cost sensitivity due to specific variables. The Value Tornado Diagrams display the change in the fuel cycle cost as each variable is changed from the low to high value setting while all other variables are held at the nominal settings. The specific low, nominal, and high costs for each variable and the resulting impact on the fuel cycle cost is shown below each of the uncertainty bars. The bars are sorted so the variables with the biggest change in cost are at the top of the diagram.

The Value Tornado Diagram in Figure 8 shows the key variables across all the strategies that are most likely to increase or decrease the lowest cost strategy. This diagram is labeled with "Case 1 Perspective" because it shows the primary cost variables that have the potential to switch the lowest cost strategy (currently Case 1) to another case as the lowest cost option. The relative cost influence is shown by the width of the bar on the chart. The variables with the greatest potential impact for increasing or decreasing the cost are located at the top of the diagram. The value shown above the center line is the cost based on all modules set to their nominal cost. The ends of each bar show the low or high value of the variable and their impact on the expected costs. For example, on the top bar label "Module A Mining and Milling" a value of 50/5.325 is at the left (low end) and 150/7.399 is at the right (high cost) end. The first numbers, 50 and 150, refer to the low and high reference values from Table 6 . The second values, 5.325 and 7.325 , refer to the new expected costs (in mills $/ \mathrm{kW} \mathrm{h}$ ) that the change in variable value would have on the final expected value. The cost range of Module A has a larger impact on the expected value of case than any of the other modules, with a potential to swing the costs plus or minus one mill $/ \mathrm{kW} \mathrm{h}$.

Some variable bars indicate a change in color from green to blue (when moving away from the center line). These variables have the potential to reduce the costs of the cases enough that the expected outcome would be less than Case 1. Since four cases are being compared together in this analysis, the chart does not identify which cases could result as the lowest cost option and at what cost point. 


\section{Value Tornado Diagram}

\section{Modue Cost Uncertainty - Case 1 Perspective}

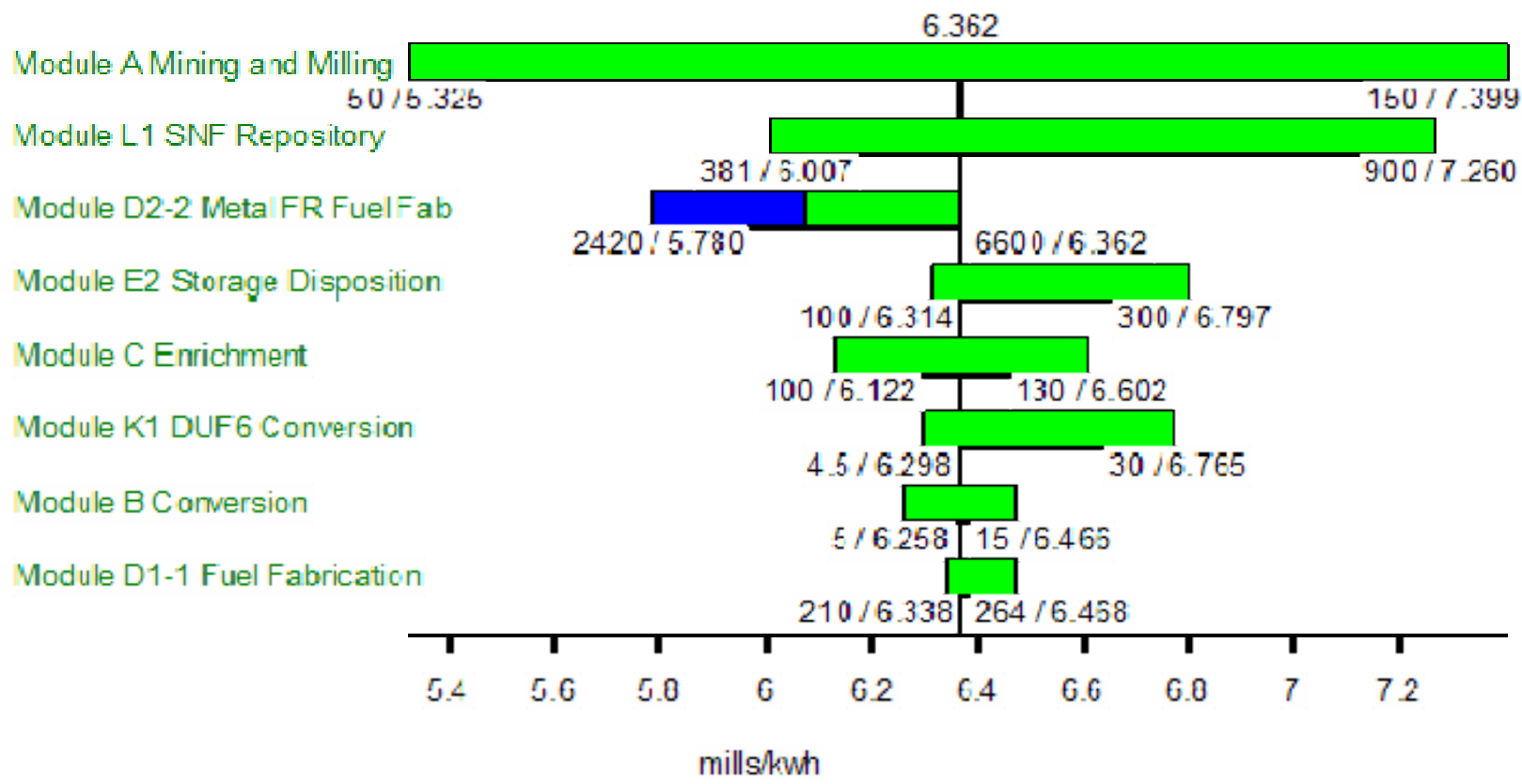

Figure 8. Value tornado diagram-Case 1 perspective.

The investigation into these questions is provided in the next set of analysis through a pair-wise comparison. These comparisons seek to clarify the influence of the variables on the different cases and help to identify the tipping points where another case could become the less expensive option. The next set of Tornado diagrams helps to expose the trade-offs between the cases. Please note that some of the largest uncertainties, for example Module A Mining and Milling, have the potential to significantly influence the case costs, but do not trip a decision point toward another case within the defined cost uncertainty. The uncertainty could be extended on any of these variables to test the affect on the lowest cost option. Figures 9 to 14 and associated discussions that follow each figure will provide the rationale behind the differences of cost between the cases. 


\section{Value Tornado Diagram}

Module Cost Uncertainty - Case 1 \& 2 Comparison

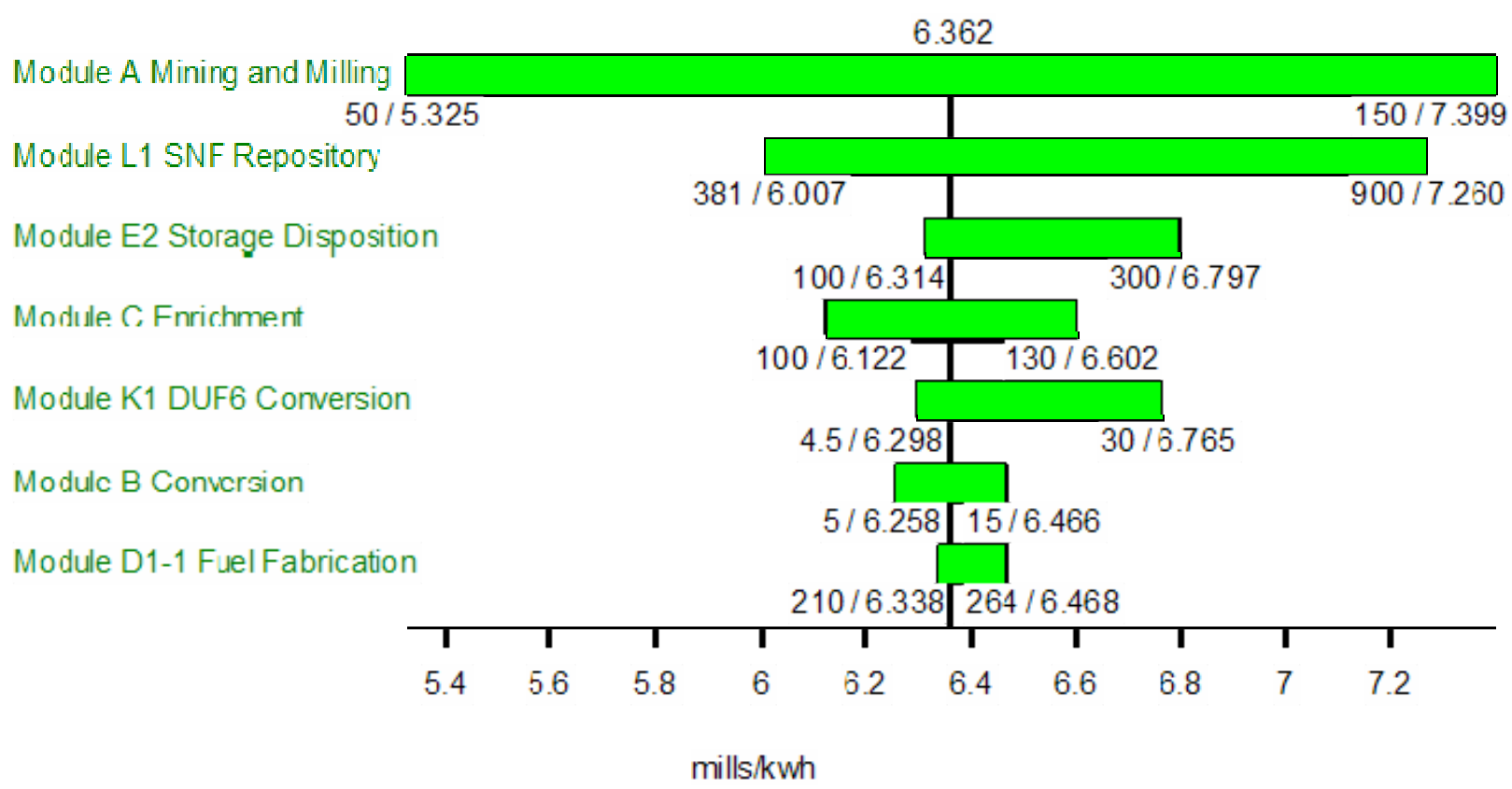

Figure 9. Value tornado diagram-Case 1 and 2 comparison.

Assessment:

- $\quad$ The Value Tornado Diagram shown in Figure 9 compares the variables for Cases 1 and 2, which have the largest cost uncertainties and the potential to switch the preferred strategy from Case 1 to Case 2.

- None of the variables suggest the potential for a change in strategy given the current range of uncertainty around each of the variables.

- $\quad$ Modules A, L1, C, and K1 are important cost contributors and can impact the fuel cycle costs by $\sim \pm 1 \mathrm{mill} / \mathrm{kW} \mathrm{h}$. Also, there may be combined or additional effects from several modules in a high or low cost state to amplify the costs.

- $\quad$ Case 1 may require greater disposal capacity than currently defined under the NWPA. The costs for a second repository have not been assessed. 


\section{Value Tornado Diagram}

Module Cost Uncertainty - Case 1 and 3 Comparıson

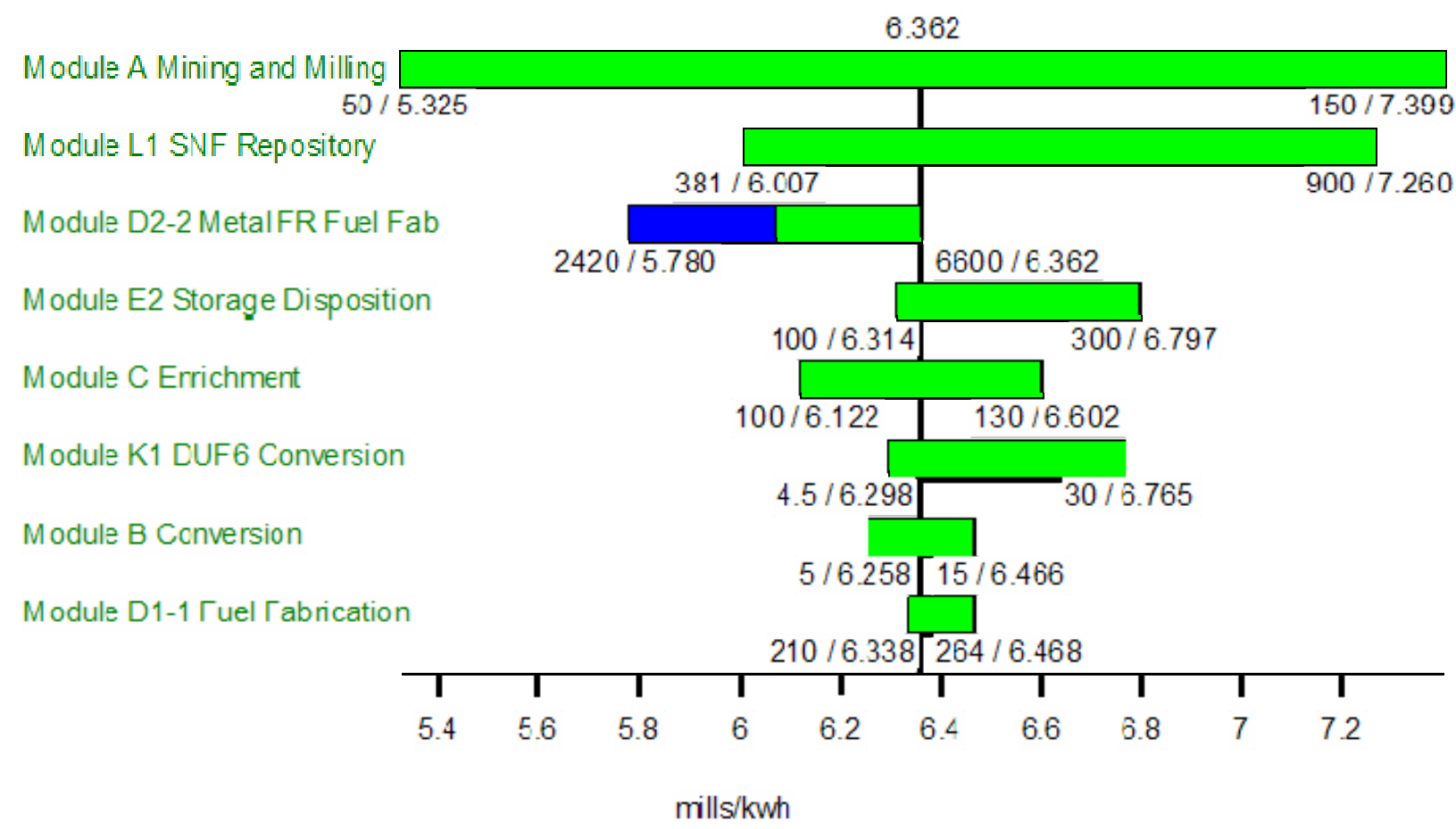

Figure 10. Value tornado diagram-Case 1 and 3 comparison.

Assessment:

- $\quad$ The Value Tornado Diagram shown in Figure 10 compares the variables for Cases 1 and 3 that have the largest cost uncertainties and the potential to switch the preferred strategy from Case 1 to Case 3.

- $\quad$ Module D2-2, the metal fast reactor fuel fabrication indicates the potential for a change in strategy. This implies that when fuel fabrication costs are in the low-nominal cost range of $\$ 2,420$ to $\$ 5,500$, the low cost option could switch to Case 3. The cost tipping point where the strategy change occurs is around $\$ 3,000 / \mathrm{KgHM}$.

- $\quad$ Modules A, L1, C, K1, D1-1, and B are also important cost contributors and can impact the fuel cycle costs by $\sim \pm 1 \mathrm{mill} / \mathrm{kW}$ h. Also, there may be combined or additional effects from several modules in a high or low cost state to amplify the costs. 


\section{Value Tornado Diagram}

\section{Module Cost Uncertanty - Case 1 \& 4 Companson}

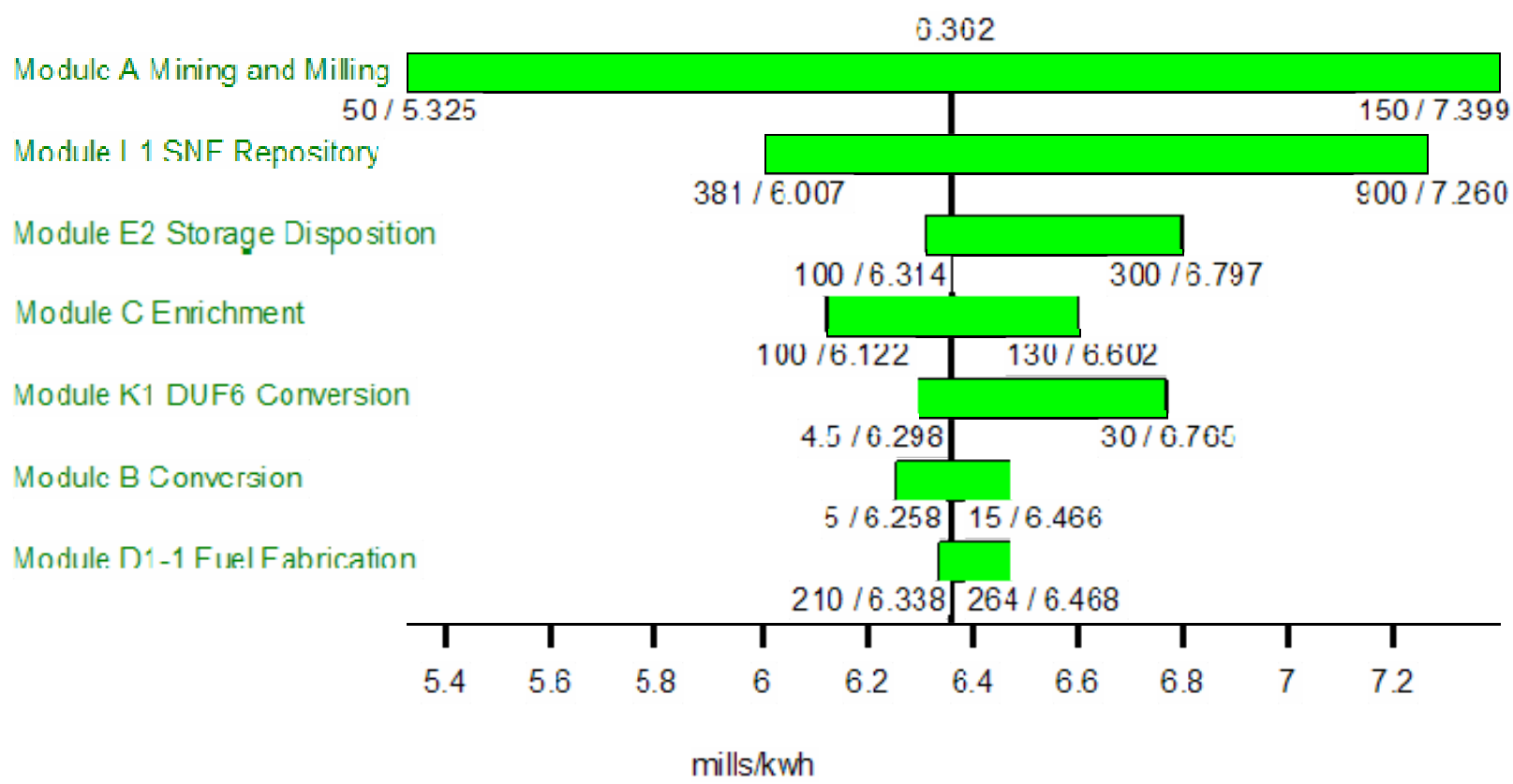

Figure 11. Value tornado diagram—Case 1 and 4 comparison.

Assessment:

- $\quad$ The Value Tornado Diagram shown in Figure 11 compares the variables for Cases 1 and 4 that have the largest cost uncertainties and the potential to switch the preferred strategy from Case 1 to Case 4 . In this case, there are no variables with a tipping point that would influence the preferred strategy.

- $\quad$ Modules A and L1 are the most important cost contributors and can impact the fuel cycle costs by up to $\sim \pm 1 \mathrm{mill} / \mathrm{kW} \mathrm{h}$. Also, there may be combined or additional effects from several modules in a high or low cost state to amplify the costs.

- $\quad$ Thermal recycling with MOX is relatively more expensive than once-thru, fast, or thermal/fast recycling. The French equate a 7\% increase in the cost of electricity for thermal recycling, which translates to a 2-4 mill/ $\mathrm{kW} \mathrm{h}$ increase. French recycling costs are based on Pu recycle, where the $\mathrm{Pu}-\mathrm{MOX}$ requires glovebox fabrication. Case 4 costs are based on $\mathrm{Pu}-\mathrm{Np}-\mathrm{Am}-\mathrm{Cm}$ recycle. Fabrication of Am and $\mathrm{Cm}$ rods requires fully remote operations, which is more expensive than fabrication of $\mathrm{Pu}$ and $\mathrm{Np}$ fuel rods. For purposes of the evaluation, it is assumed that $(\mathrm{Pu}, \mathrm{Np})$ $02 \mathrm{MOX}$ driver rods can be fabricated in facilities requiring only glovebox operations.

- $\quad$ Recycling the REPU into UOX LWR assemblies would help the economics (fuel cycle mills/kW h unit cost) of thermal recycling by a few percent, especially if the cost of uranium ore is high. Credit can be taken for avoided costs associated with standard UOX fuel assembly production; however, the associated costs of re-enriching and re-fabricating the REPU must also be accounted for. The Case 4 thermal recycle case above did not recycle REPU, rather assumed that the uranium product was converted to oxide and disposed at $\$ 12 / \mathrm{kgU}$. 


\section{Value Tornado Diagram}

Module Cost Uncertainty - Case $2 \& 3$ Comparison

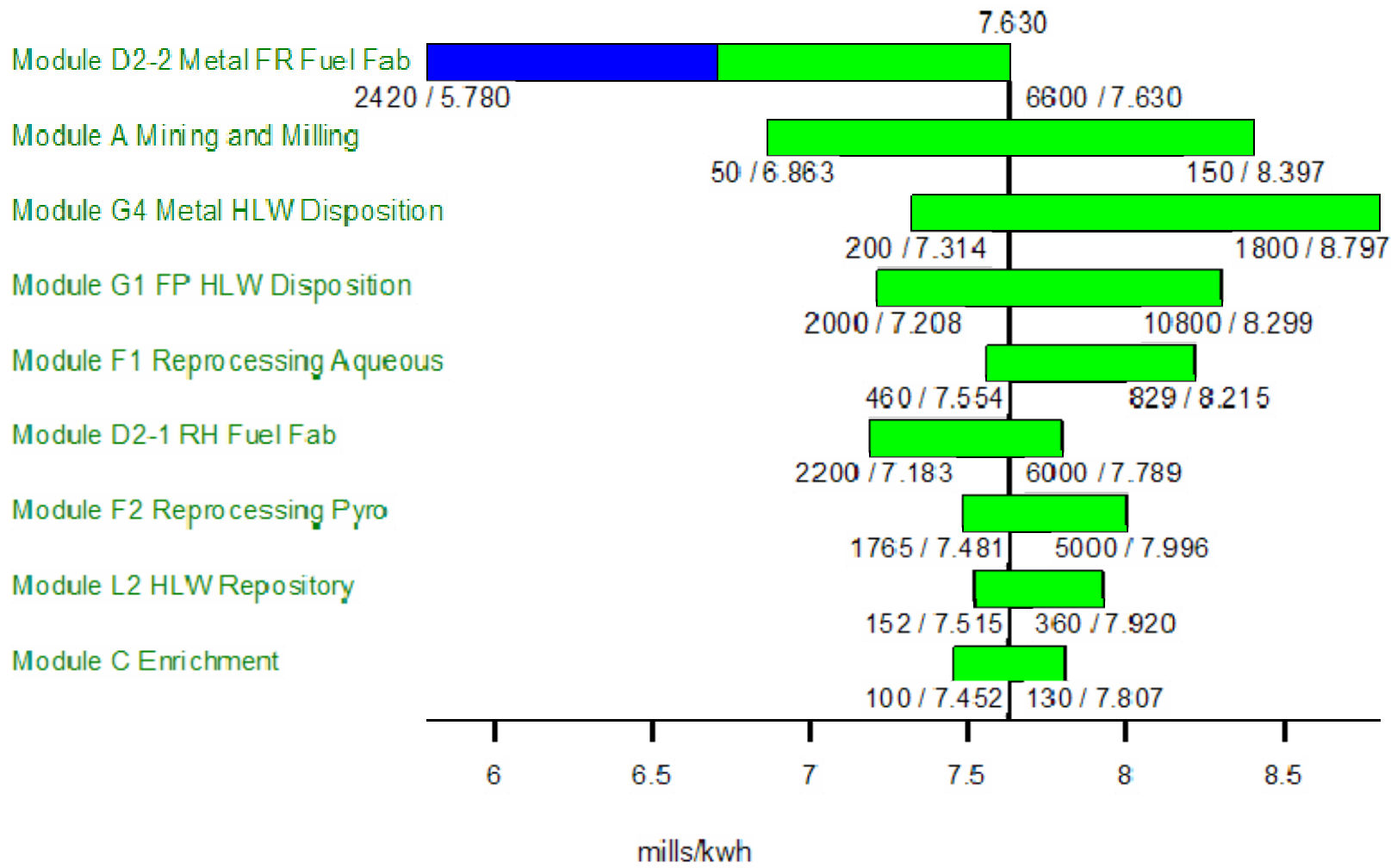

Figure 12. Value tornado diagram-Case 2 and 3 comparison.

Assessment:

- $\quad$ The Value Tornado Diagram shown in Figure 12 compares the variables for Cases 2 and 3 that have the largest cost uncertainties and the potential to switch the preferred strategy from Case 2 to Case 3.

- $\quad$ Module D2-2, the metal fast reactor fuel fabrication, indicates the potential for a change in strategy. This implies that when fuel fabrication costs are in the low-nominal cost range of $\$ 2,420$ to $\$ 5,500$, the low cost option could switch to Case 3 . The cost tipping point where the strategy change occurs is around $\$ 4,300 / \mathrm{Kg}$.

- $\quad$ Modules A, G4, G1 and are also important cost contributors and can impact the fuel cycle costs by $\sim+1.1 \mathrm{mill} / \mathrm{kW}$ h to $-0.8 \mathrm{mills} / \mathrm{kW} \mathrm{h}$. Also, there may be combined or additional effects from several modules in a high or low cost state to amplify the costs.

- The contribution to cost uncertainty from Modules F1 and F2 reprocessing is on par with the impacts from the Module D2-1 fuel fabrication, Module L2 HLW repository costs and Module C Enrichment. 


\section{Value Tornado Diagram}

Module Cost Uncertainty - Case 2 \& 4 Comparison

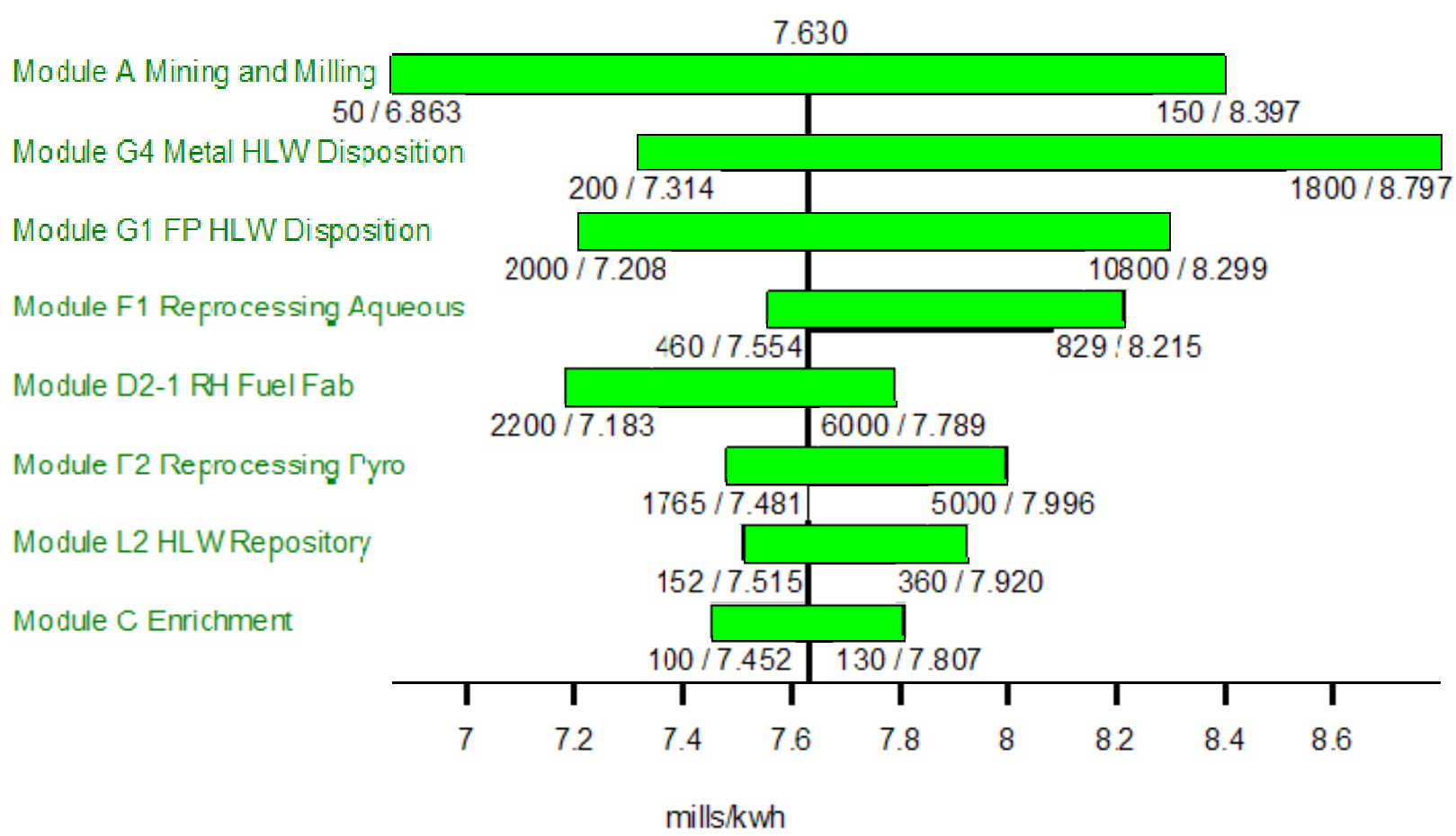

Figure 13. Value tornado diagram-Case 2 and 4 comparison.

Assessment:

- $\quad$ The Value Tornado Diagram shown in Figure 13 compares the variables for Cases 2 and 4 that have the largest cost uncertainties and the potential to switch the preferred strategy from Case 2 to Case 4.

- $\quad$ Due to the large difference between the EV of the two cases ( $8.2 \mathrm{vs} .13 .6 \mathrm{mills} / \mathrm{kW} \mathrm{h})$, there are no variables with sufficient potential to reduce the cost of Case 4 to become competitive with Case 2 .

- Modules A, G4, G1, and F1 are also important cost contributors and can impact the fuel cycle costs by $\sim \pm 1.0 \mathrm{mill} / \mathrm{kW} \mathrm{h}$. Also, there may be combined or additional effects from several modules in a high or low cost state to amplify the costs. 


\section{Value Tornado Diagram \\ Module Cost Uncertainty - Cases 3 \& 4 Comparison}

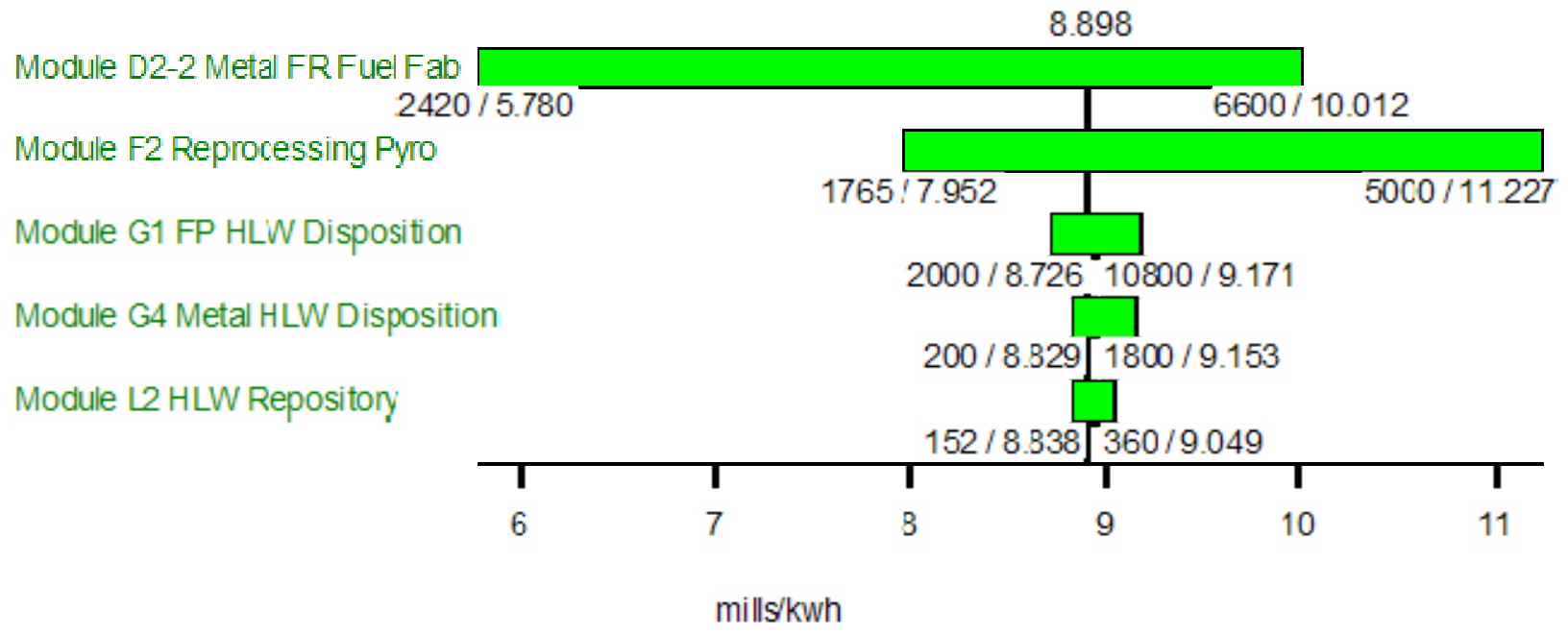

Figure 14. Value tornado diagram-Case 3 and 4 comparison.

Assessment:

- $\quad$ The Value Tornado Diagram shown in Figure 14 compares the variables for Cases 3 and 4 that have the largest cost uncertainties and the potential to switch the preferred strategy from Case 3 to Case 4.

- $\quad$ Module D2-2, the metal fast reactor fuel fabrication indicates a significant potential for cost reduction of over $3 \mathrm{mill} / \mathrm{kW} \mathrm{h}$.

- $\quad$ Module F2 is also a key cost contributor and can impact the fuel cycle costs by $\sim+2 \mathrm{mill} / \mathrm{kW} \mathrm{h}$ and $\sim-1 \mathrm{mill} / \mathrm{kW}$ h. Also, there may be combined or additional effects from several modules in a high or low cost state to amplify the costs. 


\section{THE UNIT FUEL CYCLE COST IN PERSPECTIVE TO THE OVERALL BUSBAR COST OF NUCLEAR ELECTRIC POWER AND POSSIBLE WASTE RADIOISOTOPE TRANSMUTATION MISSIONS}

The previous sections have shown that the four case fuel cycle component cost ranges vary anywhere from $5+$ mills $/ \mathrm{kW}$ h to $21 \mathrm{mills} / \mathrm{kW}$ h depending on complexity and the individual unit processing costs of the various steps. How does this compare to the overall unit cost of electricity from nuclear power, particularly from new designs for NPPs? The figure of merit for comparing new NPP technologies is usually the "busbar cost" or more precisely the "Levelized Unit Electricity Cost" (LUEC), of which the fuel cycle cost component is only one part. This number represents a cost, not a price, and is the cost of electricity at the power plant switchyard boundary (busbar), so electricity marketing and distribution costs, which would add a few cents per $\mathrm{kW} \mathrm{h}$, are not included. Generally the LUEC is broken up into four components:

- $\quad$ Reactor capital (including financing and amortization)

- Annual reactor nonfuel operations and maintenance (including the "people" costs for periodic refueling crews)

- $\quad$ Fuel cycle material and processing services, which is the majority subject and for which the range is given above.

- Annual contributions to an annualized escrow fund for eventual decontamination and decommissioning of the nuclear power plant.

The international Generation IV Reactor Systems program has sponsored the development of a spreadsheet code (G4-ECONS) for calculation of the LUEC components from very basic technology and economic information that is likely to be available during reactor development. The code can also be applied to systems that are closer to deployment, such as Generation III+ reactor systems, and for which better cost data is available. Table 10 below shows the LUEC results for a hypothetical Gen III+ PWR operating on an open 18 month UOX fuel cycle, which is similar to AFCI Case 1. The fuel cycle cost between five and six mills $/ \mathrm{kW} \mathrm{h}$ is definitely in the range of actual experience for PWR cycles today. Most importantly, the fuel cycle cost is less than $15 \%$ of the overall LUEC. For all reactor types, the capital costs associated with the reactor design, construction, start-up, and financing will continue to be the predominant component of LUEC. This capital component is heavily influenced by financing costs, which are expressed for this model via the discount rate. In Table 10, the $10 \%$ real discount rate (no inflation component) is representative of a privately financed plant in a mostly deregulated (economic deregulation, not safety deregulation) environment. If the discount rate were lowered to $5 \%$, which would imply a more regulated and less-risky environment with lower financing costs, the capital component of LUEC would be much less as is shown in Table 11. For this latter case, the fuel cycle cost, which is nearly insensitive to financing costs, would be around $20 \%$ of the total LUEC.

Another figure of merit for reactor capital is the specific overnight capital cost, which is defined as the overnight capital cost (not including interest during construction costs; as if the plant were built "overnight") divided by the reactor power capacity and is expressed in $\$ /$ kilowatt of electrical capacity. The value of $\$ 1,800 / \mathrm{kW}(\mathrm{e})$ shown in Tables 10 and 11 is considered to be very realistic, and some Far Eastern LWRs may have come in under this cost. A specific cost can also be calculated with the interest during construction included. This is often quoted for completed projects. Both types of specific cost are shown in Tables 10 and 11. 
Table 10. G4-ECONS breakdown of the LUEC for a generation III+ PWR operating on an open cycle under de-regulated higher-risk conditions (10\% real discount rate).

\begin{tabular}{|c|c|c|}
\hline \multicolumn{3}{|c|}{ Summary of Model Results including LUEC Breakdown } \\
\hline \multirow{8}{*}{$\begin{array}{l}\text { Case: Gen III+ PWR wit } \\
1300 \text { Mwe net } \\
1800 \text { \$/kwe overnight cost input incl 1st core } \\
10.0 \% \text { Discount rate for IDC \& cap rec } \\
\text { 90.0\% Avg capacity factor } \\
\text { 6.0 Design/Build/Start duration (Yr) } \\
51000 \text { Mw-d/MTHM burnup } \\
5.00 \% \text { Discount rate for D\&D sinking fd } \\
\text { 40 Plant operating life in years }\end{array}$} & Dpen Fuel Cycl & \\
\hline & & \\
\hline & & \\
\hline & & \\
\hline & & \\
\hline & & \\
\hline & & \\
\hline & & \\
\hline & Annualized & Mills/kwh or \\
\hline LUEC Cost Component & Cost in $\$ M / y r$ & $\$ / M W h$ \\
\hline Capital Cost incl Financing & $\$ 328.4$ & 32.04 \\
\hline Operations Cost & $\$ 101.9$ & 9.94 \\
\hline Fuel Cycle Cost (equilibrium reloads) & $\$ 64.9$ & 6.33 \\
\hline D\&D Sinking Fund Cost & $\$ 2.5$ & $\underline{0.24}$ \\
\hline Totals & $\$ 497.6$ & 48.55 \\
\hline Reactor Specific Capital incl financ & $(w e)=$ & 2470 \\
\hline
\end{tabular}

Table 11. G4-ECONS breakdown of the LUEC for a generation III+ PWR operating on an open cycle under regulated utility, lower-risk conditions ( $5 \%$ real discount rate).

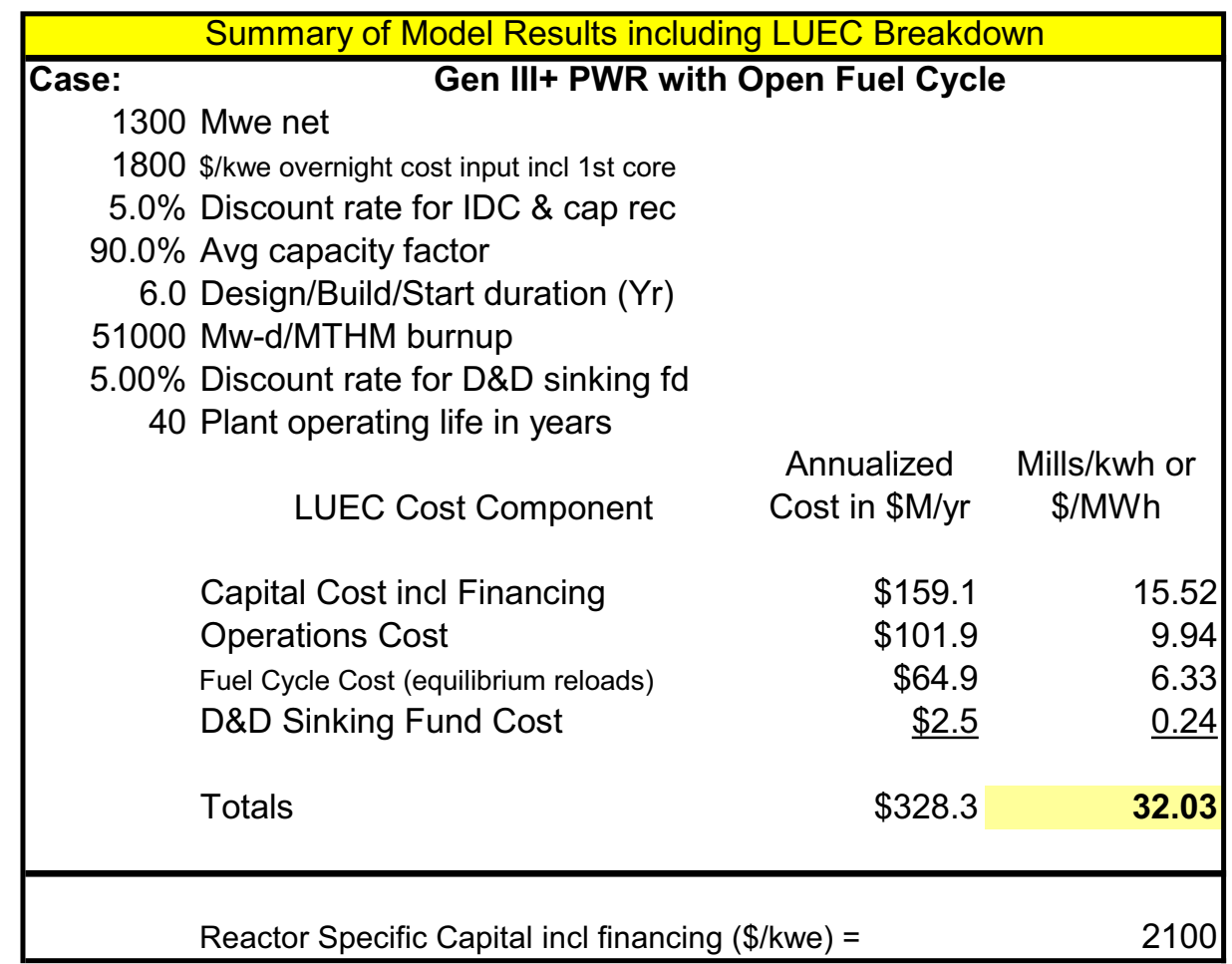


Other fuel cycle cost considerations are the implications of the higher fuel cycle unit costs (7-11 mills/kW h) such as Cases 2 and 4 for which Gen IV Reactor EMWG cases (with reactor -related costs) are not available, and for cycles which take LWR used fuel components and transmute them into UREX+ derived "powder to pellet" LWR targets, or metal-based fast reactor recycle fuel which is converted into more short-lived radioisotopes that are amenable to repository disposition. The higher fuel cycle cost is mainly attributed to the need for typical UOX front-end LWR fuel cycle steps (ore, enrichment, etc) in addition to the multiple back-end steps.

Associated with a transmutation mission are the high unit costs of fabricating "target" type fuel rods in remote-handling, hot-cell type facilities. These unit costs could be $\$ 10 \mathrm{~K}+$ per $\mathrm{kgHM}$ handled. Such higher fuel cycle costs, should not lead to dismissal of these concepts from the standpoint of economics. These cycles are performing a valuable waste management service for legacy used fuel in addition to producing electricity. Used fuel waste transmutation or "actinide burning" services should perhaps be thought of as an alternate or co-product just like hydrogen production or desalination of water is considered as an adjunct to electricity production for some reactor systems. Factoring this realization into the economics of the overall system economics should be investigated in the near future. 


\section{SUMMARY OF KEY ECONOMIC FINDINGS}

The equilibrium fuel cycle economic analysis shows large fuel cycle cost uncertainties with all the fuel cycle strategies. Further U.S. based design studies are needed, such as the ones being proposed by the Global Nuclear Energy Partnership (GNEP) to reduce the cost uncertainties with respect to the total fuel cycle costs and reactor costs. Similar design/cost studies are needed on the fast reactors since the effect of the reactor contribution (mainly reactor acquisition and non-fuel operations) to the cost of electricity is expected to greatly surpass the fuel cycle cost.

The major fuel cycle cost discriminators are uranium mining and milling costs and recycled fuel fabrication. Additional variables which have a large potential impact include the HLW/SNF repository, reprocessing, and waste conditioning. Separations costs, in spite of high cost uncertainty, are not decision drivers in these cases. The impacts of separations are on par with the costs due to process waste conditioning and disposition. For thermal/fast recycling, the combined cost impact from high end costs for aqueous and pyrochemical separations would only total about $1 \mathrm{mill} / \mathrm{kW} \mathrm{h}$. However, there are unknown cost risks due to less technical process maturity and operational experience associated with pyrochemical separations than with aqueous processing.

The insight from this analysis is that the costs for the open fuel cycle are driven by uncertainties in open-market pricing for uranium and front-end fuel services, and the policies defining the costs for used nuclear fuel disposition. Alternatively, closed fuel cycle costs are driven by technology uncertainties for "hot" (remote handling) fuel fabrication, actinide separation, and process waste disposition. In the closed fuel cycle case, resources needed to produce reactor fuels will be less sensitive to market dynamics and will produce less waste subject to disposal in geologic repositories.

Future analysis should also consider the following:

- The total cost of electricity including reactor costs. Although some preliminary and quite contrasting cost data is available from the French and the Japanese, there is broad uncertainty around the overnight capital costs for fast reactors.

- $\quad$ Additional fuel cycle alternatives, including a two-tier thermal recycle with single and multi-pass thermally recycled fuel going to fast converter reactors for additional transuranic destruction.

- Analysis of system uncertainties that influence the costs. For example, the impacts from using different conversion ratios for fast converter reactors, higher LWR/ALWR burnups, variations on reactor and separation/fabrication facility capacity factors, and separation process efficiencies.

- $\quad$ Economic trade-offs and sensitivities, for example, price points when recycling uranium becomes viable due to increases in disposal costs or an increase in natural uranium prices and trade-offs between cost optimization and proliferation resistance.

- $\quad$ Using dynamic system models, for example, VISION.ECON, to evaluate and compare costs under nonequilibrium conditions.

- $\quad$ Comparisons of nuclear energy costs to other base-load energy systems. Future fossil-based energy systems will also have cost uncertainties resulting from emission controls, carbon capture and geologic sequestration, hydrogen production, and international market fluctuations affecting the costs of fossil fuels. 


\section{REFERENCES}

42 U.S.C. 6901, 1976, "Resource Conservation and Recovery Act,” United States Code.

42 U.S.C. 10101, Amended March 2004, "Nuclear Waste Policy Act," United States Code.

DOE, 2006, U.S. Department of Energy Advanced Fuel Cycle Initiative (AFCI) Comparison Report, FY 2006 Update, July 2006.

DOE, Office of Civilian Radioactive Waste Management, 2001, Analysis of the Total System Life-cycle Cost of the Civilian Radioactive Waste Management Program, DOE/RW-0533, May 2001.

Bunn, M. et al., (Harvard University), 2003, The Economics of Reprocessing vs. Direct Disposal of Spent Nuclear Fuel; Project on Managing the Atom, DE-FG26-99FT4028, December 2003.

Electric Power Research Institute (EPRI), 2006, Program on Technology Innovation: Room at the Mountain - Analysis of the Maximum Disposal Capacity for Commercial Spent Nuclear Fuel in a Yucca Mountain Repository, May 2006.

Miller, K. and K. A. Williams, Economic Modeling Working Group (EMWG), 2006. “A User's Manual for G4-ECONS: A Generic EXCEL - Based Model for Computation of the Projected Levelized Unit Electricity Cost (LUEC) from Generation IV Reactor Systems," Commissioned by the Generation IV International Forum, May 2006.

Shropshire, D., et al., 2006, "2006 Advanced Fuel Cycle Cost Basis”, INL/EXT-06-11536, Official Use Only under FOIA Exemption 5, July 2006. 
Appendix A

\section{Fuel Cycle Cost Comprehensive Spreadsheet}




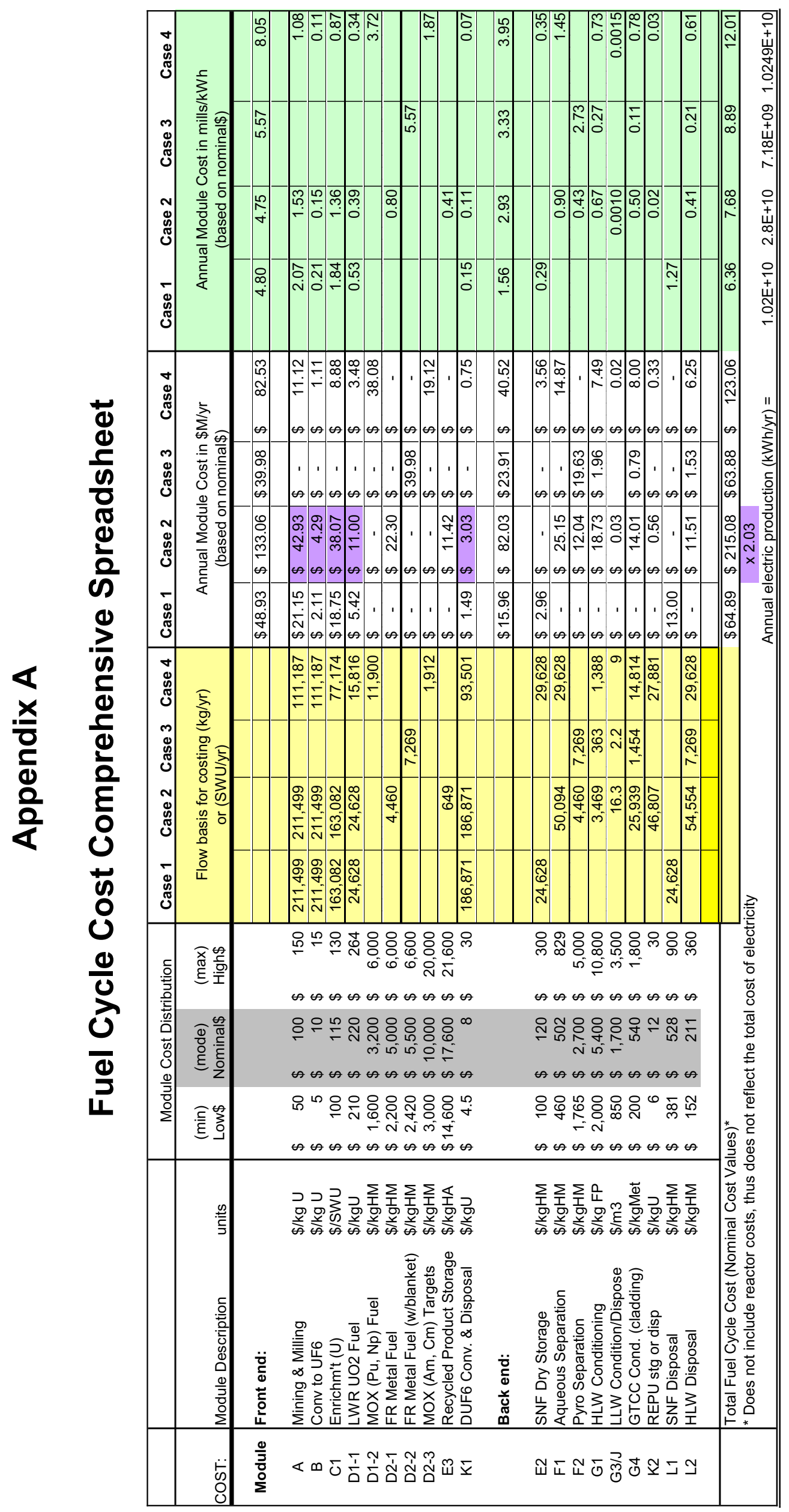

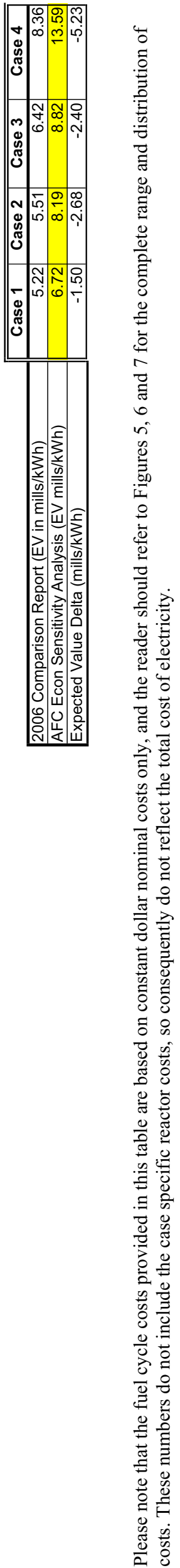

